University of Louisville

ThinkIR: The University of Louisville's Institutional Repository

$12-2015$

\title{
Comparison of digital scanning and polyvinyl siloxane impression techniques by DMD students : instructional efficiency and attitudes toward technology.
}

Alexander M. Marti

University of Louisville

Follow this and additional works at: https://ir.library.louisville.edu/etd

Part of the Prosthodontics and Prosthodontology Commons

\section{Recommended Citation}

Marti, Alexander M., "Comparison of digital scanning and polyvinyl siloxane impression techniques by DMD students : instructional efficiency and attitudes toward technology." (2015). Electronic Theses and Dissertations. Paper 2338.

https://doi.org/10.18297/etd/2338

This Master's Thesis is brought to you for free and open access by ThinkIR: The University of Louisville's Institutional Repository. It has been accepted for inclusion in Electronic Theses and Dissertations by an authorized administrator of ThinkIR: The University of Louisville's Institutional Repository. This title appears here courtesy of the author, who has retained all other copyrights. For more information, please contact thinkir@louisville.edu. 


\title{
COMPARISON OF DIGITAL SCANNING AND POLYVINYL SILOXANE IMPRESSION TECHNIQUES BY DMD STUDENTS: INSTRUCTIONAL EFFICIENCY AND ATTITUDES TOWARDS TECHNOLOGY
}

$$
\text { By }
$$

\author{
Alexander M. Marti \\ University of Louisville School of Dentistry, 2015
}

\begin{abstract}
A Thesis
Submitted to the Faculty of the University of Louisville School of Dentistry

In Partial Fulfillment of the Requirements for the Degree of
\end{abstract}

Master of Science in Oral Biology

Department of Oral Biology

University of Louisville

Louisville, Kentucky

December 2015 

COMPARISON OF DIGITAL SCANNING AND POLYVINYL SILOXANE IMPRESSION TECHNIQUES BY DMD STUDENTS: INSTRUCTIONAL EFFICIENCY AND ATTITUDES TOWARDS TECHNOLOGY

\author{
By
}

Alexander M. Marti

B.A., University of Louisville, 2008

M.D., University of Louisville, 2012

A Thesis Approved on

July 6, 2015

By the following Thesis Committee:

Dr. Wei-Shao Lin, Thesis Co-Director

Dr. Bryan T. Harris, Thesis Co-Director

Dr. William C. Scarfe, Committee Member

Dr. Michael J. Metz, Committee Member

Dr. Dean Morton, Committee Member 


\section{DEDICATION}

I dedicate my thesis work to my family and many friends and colleagues. I would like to thank my parents, Miguel and Judy Marti, for instilling within me the values of hard work and education as the method of advancing in this life. A big thanks to my siblings; Chris, Anthony, and Michelle, for creating an environment of positive competition and camaraderie which would provide equal parts fuel for improvement and excitement for every success. A most special thanks to my wife and best friend, Dr. Lauren E. Spencer, with whom I have agreed to share every one of life's successes and failures. She supports me when things get difficult and continues to make me a better person every day. 


\section{ACKNOWLEDGEMENTS}

I would like to express my deepest appreciation for my research co-directors Dr.

Wei-Shao Lin and Dr. Bryan T. Harris for providing me with the opportunity to perform research that was both interesting and enjoyable. Without their knowledge and experience this research would not have been possible.

A special thanks to Dr. Lin for guiding me in the design, execution, and writing of this thesis. Your mentorship was invaluable.

To Dr. Harris for righting my ship when my sails needed wind.

To Dr. William C. Scarfe for helping me manage the inception of this thesis and for helping me navigate the ironically named electronic submission system, BRAAN2.

To Dr. Michael J. Metz his encouragement and kind words.

To Dr. Dean Morton for helping me understand the value of science in research.

To Dr. Darling for sometimes being difficult, but always being understanding. 


\begin{abstract}
COMPARISON OF DIGITAL SCANNING AND POLYVINYL SILOXANE IMPRESSION TECHNIQUES BY DMD STUDENTS: INSTRUCTIONAL EFFICIENCY AND ATTITUDES TOWARDS TECHNOLOGY
\end{abstract}

\author{
Alexander M. Marti
}

July 6, 2015

The aim of this research was compare the ability of dental students to learn an digital scanner (3M LAVA) and material-based (PVS) impression techniques and to determine attitudes and preferences towards each. D2 dental students $(n=25)$ were recruited and instructed on the use of 3M LAVA and PVS techniques using three pedagogic methods: 1) video lecture (P1), 2) investigator-led demonstration (P2), and 3) independent clinical exercise (P3). The amount of time for each pedagogic method was measured, averaged ( \pm s.d.) and compared using Wilcoxon Signed-Ranks tests. A preand post-test was administered assessing their attitudes towards both techniques using a Likert scale and compared using dependent t-tests. Instructional time for 3M LAVA was higher for each pedagogic method (P1; 15.95 vs.10.07 $\min , p=0.0000: \mathrm{P} 2 ; 8.68$ vs. 4.51 $\min , p=0.000$ : $\mathrm{P} 3 ; 20.37$ vs. $14.17, p=0.000)$. Prior to instruction, students were more familiar with the PVS techniques (3.96 vs. $1.95, p=.0000)$ and expected both to be similar in difficulty (3.52 and 3.84, $p=.106)$. After instruction, PVS techniques were considered easier to perform than expected $(4.08, p=.002)$ with no change in perceived difficulty for 
3M LAVA (3.56, $p=.106) .96 \%$ of participants expected 3M LAVA to become their primary impression technique in their career. 
TABLE OF CONTENTS

PAGE

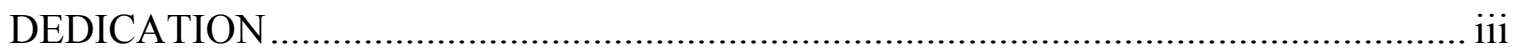

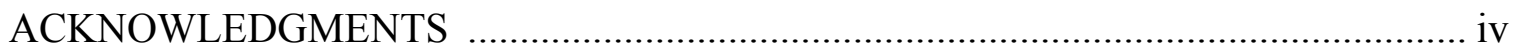

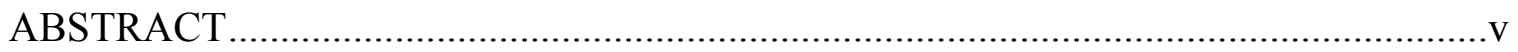

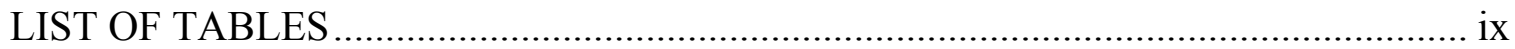

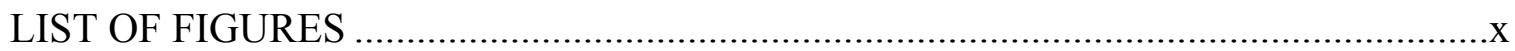

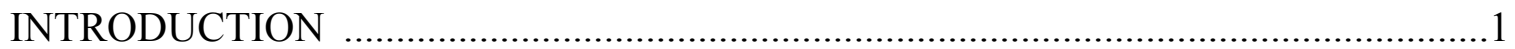

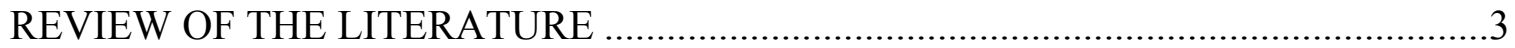

Reduction in Negative Patient Experience ……...................................................4

Positive Patient Experience..............................................................................

Increased Clinical Efficiency .....................................................................6

Accuracy of Fabricated Restorations ............................................................

Need for Pedagogical Adoption........................................................................ 12

Significance of Current Study.............................................................................16

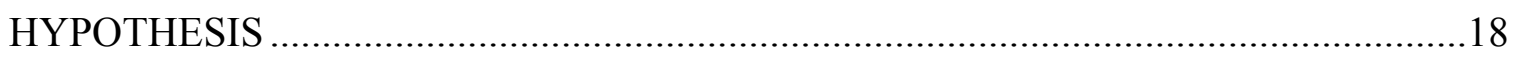

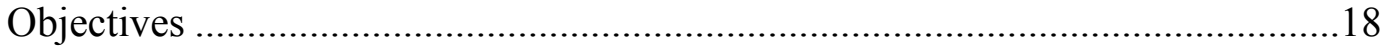

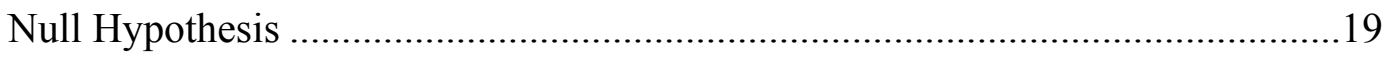

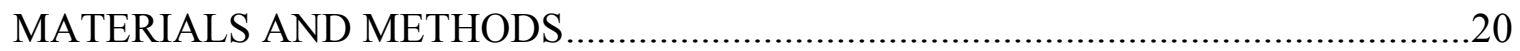

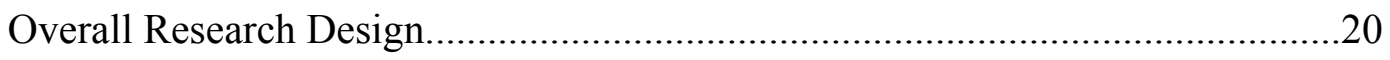




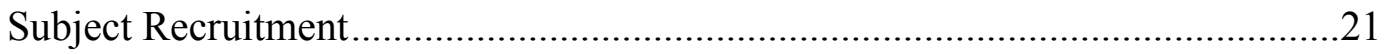

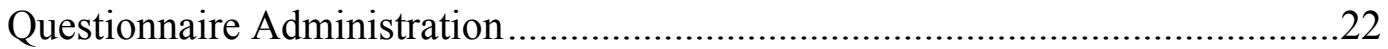

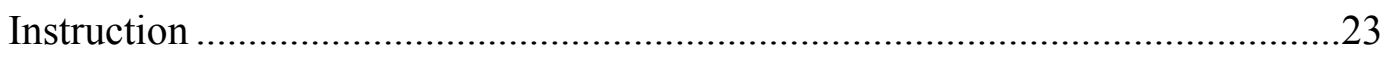

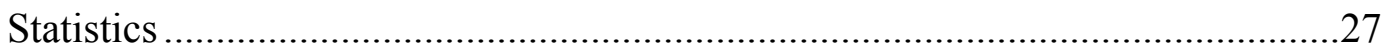

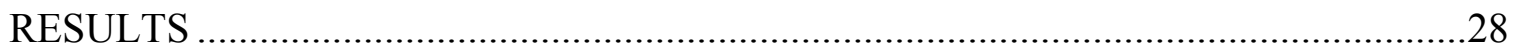

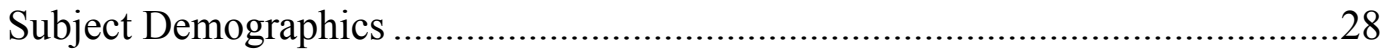

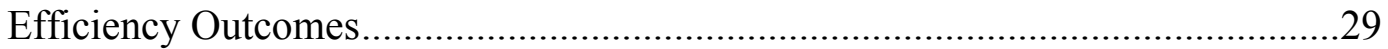

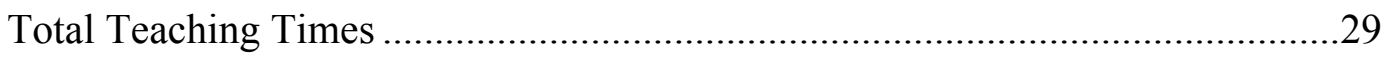

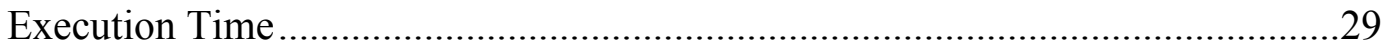

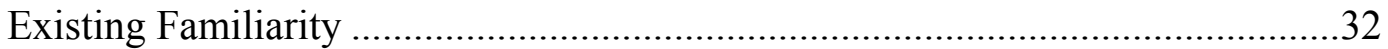

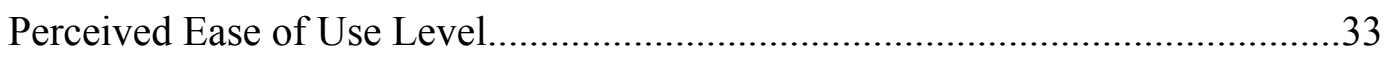

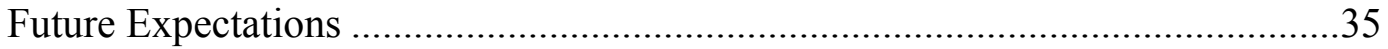

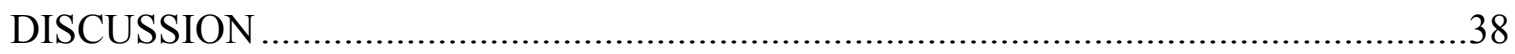

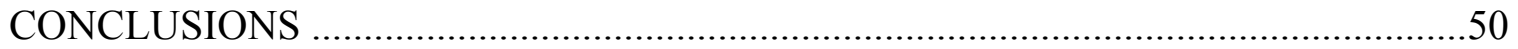

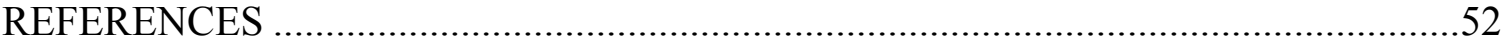

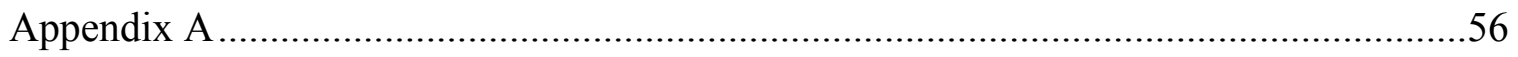

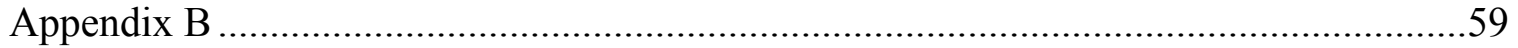

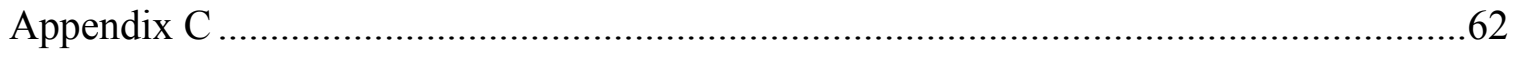

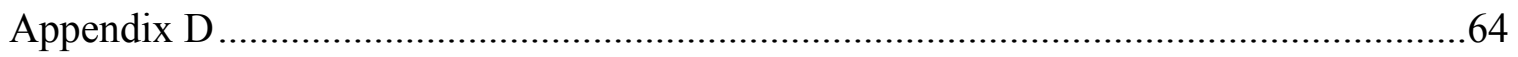

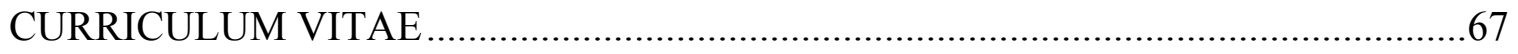




\section{LIST OF TABLES}

TABLE

PAGE

1. Demographic information........................................... 29

2. Efficiency outcomes measured in time................................... 32

3. Participants' existing familiarity with impression techniques.................. 33

4. Perceived Ease of Use Level between two Impression Techniques................ 34

5. Student's Perceived Ease of Use Level before and after exposure............... 35 


\section{LIST OF FIGURES}

FIGURE

PAGE

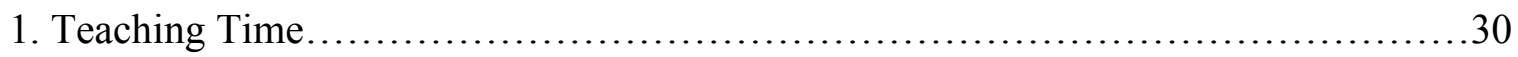

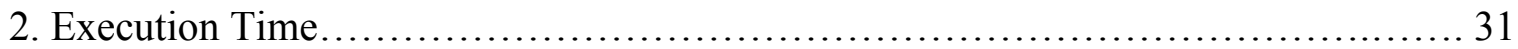

3. Existing Familiarity with Technology and Impression Techniques................... 33

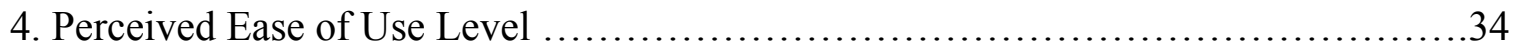

5. Current and Future Expectations.................................................. 37 


\section{CHAPTER 1}

\section{INTRODUCTION}

The first commercially available computer-assisted design/computer-assisted manufacture (CAD/CAM) system for the in-office fabrication of coronal dental restorations was introduced in 1985 (CEREC, Sirona Dental Systems St. Paul, MN, USA) (Poticny and Klim 2010). Since then, the price of dental CAD/CAM technology has greatly reduced, the accuracy of fit of restorations has markedly improved, and the number of available systems grown substantially (Luthardt et al. 2005).

While all CAD/CAM systems provide an intra-oral digital scanning system, they can be divided according to the availability of in-office or chairside subtractive manufacturing (also referred to as milling) (Fasbinder 2012). Both types of CAD/CAM systems are gaining acceptance by dental practitioners and their patients. Wismeijer et al. (2013) reported that patients significantly prefer digital scans as compared with materialbased, conventional impression techniques.

Academic dental institutions should provide instruction to students such that:

"Graduates should be able to evaluate, assess, and apply current and emerging science and technology to reflect contemporary practice." (Commission on Dental Accreditation 2013)

In relation to restorative dentistry, this implies that students be provided with opportunities to integrate digital scanning technology into their clinical experiences. 
While material based impression techniques have yet to become obsolete, educational institutions should take the initiative to concomitantly provide instruction on both digital scanning and material based impression modalities. However practical implementation into curricula will most likely include the need for more instructional time, greater faculty competency and data handling issues. More specifically, one must consider the time necessary for a student to learn how to operate a scanner effectively and perform a clinically acceptable scan. The introduction of additional classroom hours of didactic instruction and the provision of small group or one-on-one instruction in the simulation laboratory will require careful planning. Additionally, patient information databases need to be equipped with the software to import and preserve the impressions scanned so that the scanning unit does not become an anchor that impedes the educational process. If future research into this technology is to grow, it would be beneficial to expose young dental students so that their curiosity may lead to more research and a deeper understanding of what value these systems can provide to dentistry, as well as to provide dental students with a smoother transition into the workplaces of the future. 


\section{CHAPTER 2}

\section{REVIEW OF THE LITERATURE}

Numerous chair-side digital scanning systems have been introduced to the dental market, each with unique scanning modalities, milling and clinical operation protocols. Ting-Shu and Jian, (2014) provide a comprehensive overview of the five main commercial digital scanning systems currently available:

1. CEREC (Sirona Dental Systems Inc, Long Island City, NY, USA)

2. LAVA C.O.S. (3M ESPE, St. Paul, MN, USA)

3. True Definition (3M ESPE, St. Paul, MN, USA),

4. iTero (Align Technology Inc, San Jose, CA, USA), and

5. E4D (Planmeca, Helsinki, Finland).

Although each system has unique scanning and data processing technologies, they share many common characteristics. Digital scanning systems have shown great clinical efficiency and are reported to be less uncomfortable to patients, especially those with previous negative experiences with material-based impression techniques. Furthermore, just like any new technology, the effective use of these systems involves time and patience to overcome the operator learning curve (Farah 2009) 


\section{Clinical Advantages of Digital Scanning Systems}

\section{Reduction in negative patient experience}

A Dutch study looked at the prevalence of fears and phobias among Netherlanders and found that fear and phobia of dentistry represents a real problem (Oosterink et al. 2009). They surveyed 1,959 Dutch residents and reported that $24.3 \%$ of respondents were fearful of dentistry. Although this was only the $4^{\text {th }}$ most common fear, dentistry still ranked as the \#1 source of phobia. Phobia is an extreme version of fear which is a diagnosable psychiatric condition based on criteria from the Diagnostic and Statistical Manual of Mental Disorders (DSM-IV). Dental fear was rated as more severe than any other, and was the fear most commonly associated with intrusive re-experiencing. It is likely this fear of dentistry is born from negative experiences (Locker et al. 1996), although not necessarily painful ones, as some may assume. Their research shows that dental fear and anxiety is derived more so from embarrassing or frightening experiences than painful ones. Of those reporting direct negative experiences, $71.3 \%$ reported painful experiences, yet only $13.4 \%$ of patients with painful experiences were dentally anxious. $25.7 \%$ of patients with embarrassing experiences and $23.5 \%$ with frightening experiences, reported being dentally anxious. They did not look into the particular types of experiences that were interpreted as frightening or embarrassing. Yet the gagging sensation is an experience commonly cited by patients as uncomfortable and is associated with material based impression methods.

Akarslan et al. (2013) demonstrated a link between the severity of gag reflex and dental anxiety, but failed to demonstrate any correlation between gag reflex (as a 
perceived negative experience) and the patient's dental attendance. This study may be accused of inclusive selection bias in that the survey was only given to patients who were already in the dental office. It might be expected that patients who visit the dentist would be more inclined to have done so in the past, and continue to do so in the future.

In a longitudinal study by Maggirias and Locker (2002) patients filled out baseline questionnaires, including a Dental Anxiety Scale, Dental Belief Survey, the Iowa Dental Control Index, and again after 5 years. Those with more sporadic dental attendance and those who all together avoided the dental office were more likely to become anxious about dental treatment. As Akarslan et al. noted (2013), aversion to the experience of gagging may be associated with dental anxiety. This study goes on to conclude that dental anxiety leads to avoidance of the dental office. More focused studies would be needed to elucidate the direct effect conventional dental impressions have on patient comfort, the creation of fear or avoidance behaviors, and the effect these have on attendance and promptness of seeking appropriate dental care.

\section{Positive patient experience}

Even patients without dental anxiety may benefit from digital impression techniques.

Wismeijer et al. (2013) performed a patient-centered clinical study that reported significantly greater patient preference for Digital scanning technique compared with material based techniques. They used a non-random sampling process to recruit 30 patients in a private-office setting. Two self-developed 7-item post-test questionnaires were used to document patient responses on a 10-point scale to experiences after material based and digital scanning (iTero (Align Technology Inc, San Jose, CA, USA)) 
impressions were taken. Because a non-random sampling process was used, the results of the inferential statistics should be interpreted cautiously as generalizability is considered to be 'limited.' They also found that the overall time involved with digital scans was longer and more negatively perceived by patients than the material based impression. Yuzbasioglu et al. (2014) recruited 24 subjects as simulated patients (12 females, 12 males) from the first year dental and medical students in the İstanbul Medipol University to evaluate the effectiveness, clinical outcomes, and patient preferences and attitudes towards digital scanning and material based impression techniques. Some potential bias may be present as participants were students with no dental treatment needs, and volunteered for this investigation. They also measured total treatment time to evaluate the efficacy of both impression techniques. Student technique preferences and attitudes were assessed with 9-item comparative questionnaire. The reliability and internal consistency of the questionnaires were tested on a representative sample of 10 patients with the result of Cronbach Alpha reliability coefficient $>0.9$, using a pilot questionnaire, potentially elevating the reliability for the results when compared with similar research. They showed that the digital scanning technique required significantly less treatment time. Participants (simulated patients) showed significant preference in favor of the digital scanning technique. Similar to the results from Wismeijer et al. (2013), subjects preferred digital scanning techniques. Unlike the former study, which used LAVA C.O.S. (3M ESPE, St. Paul, MN, USA), this study used the CEREC Omnicam (Sirona Dental Systems Inc, Long Island City, NY, USA) digital scanning system which requires powder for data collection.

\section{Increased Clinical Efficiency}


The clinical time associated with chair-side digital scanning systems is likely to play an important role in the adoption of this new technology. Currently there is a dearth of information on the learning curve and efficiency associated with digital scanning techniques overall and specific technologies in particular.

Farah and Brown (2009), editors of Dental Advisor, used the 3M ESPE LAVA C.O.S. after a two-day training session provided by representatives of the company. Day one was an informational, including practice scanning on typodonts and staff members. On the second day patients were scheduled for crown, bridge, and onlay procedures. The researchers estimated their Net Impression time (defined as the time needed to mix the material, load the tray, time in the mouth, take an opposing impression and a bite registration) to be 9 minutes and estimated Total Impression time (defined as Net Impression time plus the time needed for assistant set-up and appropriate tray selection) to be 13 minutes. The digital scan times showed a decrease in time requirement as additional scans were taken and operators became more experienced. After 15-20 scans operators were able to average between 4 - 5 minutes of Net Scan time, a 50\% timesaving on the conventional method. Total Scan time continued to decrease past 20 attempts as the staff and operator worked more efficiently together. Additionally, patients were asked about their preferences. Of 122 patients who experienced both impression techniques, $75 \%$ preferred the digital scan, with $17.5 \%$ having no preference. The authors also compared the restorations of 63 teeth prepared for crowns using 10 clinical parameters and found restorations made using digital scans to be more accurate with a better fit.

Gimenéz et al (2013) used the LAVA C.O.S (3M ESPE, St. Paul, MN, USA) and suggested that clinical experience has a great deal to do with reducing chairside time. 
They proposed that an inexperienced operator gets significantly quicker following their $8^{\text {th }}$ attempt. Galhano et al. (2012) claim the Cerec Bluecam (Sirona Dental Systems Inc, Long Island City, NY, USA), in automatic capture mode, is capable of taking an impression of one quadrant is less than a minute and opposing arch impressions in only seconds. These claims suggest that, despite the differences in acquisition technology, digital scanning systems can generally be used clinically with reduced chair-side time as compared to material based impression techniques. Assuming the operator is highly skilled, the only limitation and potential distinguishing parameter is method and speed of acquisition. Video data acquisition has the potential for faster impressions than individual pictures. CEREC Bluecam's (Sirona Dental Systems Inc, Long Island City, NY, USA) automatic capture mode is an attempt to emulate video capture by removing the prompts from between individual images in order to make data capture more freestyle.

Clinical efficiency of digital scanning techniques is likely to be system-specific. The LAVA C.O.S. (3M ESPE, St. Paul, MN, USA) system requires a layer of reflective scan powder before scanning, while others, such as the iTero (Align Technology Inc, San Jose, CA, USA) does not. However, the former system acquires data in video format, while the latter acquires data using still-frame images. Future research is required to determine the comparable clinical efficiency of various digital impression systems.

\section{Accuracy of Fabricated Restorations}

The accuracy of restorations made with digital scanning and milling techniques as compared to material-based and lost wax technique is an important clinical consideration as regards the efficacy and adoption of digital technologies. If digital scanning fails to offer comparable accuracy, time and money will be wasted. The accuracy of digital 
scanning techniques will depend on, among other factors, the limitations of image acquisition, specific system type and use (e.g. single tooth vs. multi-teeth restorations, implant abutment vs. tooth preparation. Seelbach et al. (2012) compared 10 single, full ceramic crowns produced by three of the leading CAD/CAM systems (LAVA C.O.S. in LAVA Zirconia (3M ESPE, St. Paul, MN, USA), CEREC in Empress CAD (Sirona Dental Systems Inc, Long Island City, NY, USA), and iTero in Copran Zr-i (Align Technology Inc, San Jose, CA, USA), as well as single-step and 2-step putty wash material-based impression techniques. For material-based impression techniques, 20 crowns were manufactured, 10 in LAVA Zirconia (3M ESPE, St. Paul, MN, USA) and Noble alloy metal-ceramic (Cera E (Elephant Dental BV, Hoorn, Netherlands)). Clinically acceptable (as measured by internal fit and accessible marginal inaccuracy) single-crown restorations were fabricated using all three digital systems. Mean internal fit for all techniques were within the range of $29 \pm 7 \mu \mathrm{m}$ (LAVA C.O.S (3M ESPE, St. Paul, MN, USA) and 88 $\pm 20 \mu \mathrm{m}$ (CEREC (Sirona Dental Systems Inc, Long Island City, NY, USA)). Mean accessible marginal values for all techniques were smaller, ranging from $30 \pm 17 \mu \mathrm{m}$ (CEREC (Sirona Dental Systems Inc, Long Island City, NY, USA)) and $68 \pm 29 \mu \mathrm{m}$ (two-step putty wash, Cera-E, (Elephant Dental BV, Hoorn, Netherlands)). The authors stated that, based on their results, the average fit of a CAD/CAM crown is comparable to that of a crown produced by material based impression techniques. Some authors (Neves et al. 2014, Anadioti et al. 2014) have demonstrated better single crown accuracy with material based techniques techniques while others (Tidehag et al. 2014, Seelbach et al. 2012) show comparable accuracy with single crown restorations made with digital scanning techniques. Noteworthy however is that all authors provide results 
with clinically acceptable measurements of fit and accuracy with single crown restorations.

Abdel-Azim et al. (2014) compared material-based and digital abutment-level implant impressions for single tooth restorations and full-arch frameworks. They found that the material-based, conventional pathway produced smaller mean marginal discrepancies for single implant restorations, and the digital scanning, milled fabrication pathway produced smaller marginal discrepancies for full-arch frameworks. Mean marginal discrepancy of single unit crowns for scanning and material-based impressions was $61.43 \mu \mathrm{m}$ and $24.1 \mu \mathrm{m}$ respectively and for full-arch frameworks $63.14 \mu \mathrm{m}$ and 135.1 $\mu \mathrm{m}$ respectively. However, over the long-term, Al Quran et al. (2012) suggest that an open-impression technique with splinted impression posts provides superior accuracy.

Silva et al. (2013) investigated the fit of long-span indirect restorations and compared marginal and internal fit of 4-unit bridges. They used the LAVA C.O.S (3M ESPE, St. Paul, MN, USA) and dedicated 3M design software (3M ESPE, St. Paul, MN, USA), a comparable milling machine (LAVA CNC 500 (3M ESPE, St. Paul, MN, USA)), and sintering furnace (LAVA Furnace 200 (3M ESPE, St. Paul, MN, USA)) to produce 12 all-zirconia frameworks. Zirconia frameworks were also produced using polyether impressions (Impregum Penta Medium Body (3M ESPE, St. Paul, MN, USA)). As is common practice in dental laboratories, stone models were produced, digitally scanned (LAVA Scan ST (3M ESPE, St. Paul, MN, USA)) and zirconia models produced. Replicas were made according to established techniques (Boening and Wolf 2000, Molin and Karlsson 1993). The digital scanning technique demonstrated generally better internal fit over material-based impressions, however statistical difference was equivocal. 
Ender and Mehl (2011) compared full-arch scans for long-span accuracy. They measured both trueness and accuracy with LAVA C.O.S (3M ESPE, St. Paul, MN, USA) and CEREC Bluecam (Sirona Dental Systems Inc, Long Island City, NY, USA) and material based impression techniques using Impregum Penta (ASA Dental, Lucca, Italy). They found precision to be equal and trueness to be slightly better with the chairside digital scanning system. In a similar study (Ender and Mehl, 2015), they measured full arch impressions across a broader range of impression materials and found that the material used significantly influenced the accuracy of fit. Some conventional materials produced higher levels of accuracy than the scanning methods tested (CEREC Bluecam (Sirona Dental Systems Inc, Long Island City, NY, USA), iTero (Align Technology Inc, San Jose, CA, USA), LAVA C.O.S (3M ESPE, St. Paul, MN, USA).

Kim et al. (2013) investigated the accuracy of digital scans (iTero (Align Technology Inc, San Jose, CA, USA)) to material-based impressions comparing the accuracy of dies fabricated on a stereolithographic (digital) and stone (material-based) models compared to a master cast. They found comparable dimensional differences between techniques (digital scanning, $23.9 \pm 17.6$; material based impression, $17.6 \pm$ 45.6) $\mu \mathrm{m}$ and concluded that digital scanning provides adequate accuracy for clinical application.

The current literature supports the use of chairside digital scanning techniques for single unit restoration and, in some instances suggests that this may be optimal for longer span restorations (e.g. Abdel-Azim et al. 2014). However the dimensional stability over time of polyvinyl siloxane material is still highly regarded (Nassar et al. 2013). 


\section{Need for Pedagogical Adoption}

Adoption of new clinical techniques with evidence-based efficacy should be adopted into the curriculum of dental education. Pedagogic implementation of digital scanning techniques requires additional instructional (didactic and simulation laboratory) and clinical time. This will soon become a necessity as this technology overshadows conventional material based techniques in private dental practice. Therefore educational experiences for dental students must include exposure to chairside digital scanning technologies to ensure contemporary competency.

The majority of dental clinical education is provided in lecture format. The average dental student spends approximately 2,000 hours sitting in lectures during their dental school career (Hendricson 2012). In a review of the Institute of Medicine's report entitled Dental Education at the Crossroads: Challenges and Change, Hendricson (2012), evaluated the success of the initiatives outlined and calls for many varieties of reform in dental education so that dental education may be better matched with the modern student. One change he suggests is that educators "make online learning an entrée instead of a side dish" to better conform with Generation Y students who desire ATAW (anytime, anywhere) access to educational materials. The digital revolution in the dental workplace reflects the societal trend for the adoption of digital innovation - a fashion that is strong amongst the modern student. Many would suggest that it only makes sense that educational practice be modified to the strengths of those whom we teach. The question however is how best to implement this approach.

Janda et al. (2005) sought to shed light on the manner of video presentation that would be most successful with dental students. Teaching a simple procedure, surgical 
hand-washing, they evaluated performance, attitudes, and written exam outcomes following multiple formats of video presentation. No difference was found in their performance of the simple procedure, but both methods of video teaching were well received by the students.

What about more advanced topics in oral and maxillofacial implantology? The answer might be 'yes.' Eitner et al. (2008) divided 95 dental students into two groups. One group was educated in a traditional fashion with a professor lecturing before a group of students. The other group learned through an interactive program named mobiTED (Dok-IN gmbH, Nuremberg, Germany), which represents computer-aided learning and computer-aided testing. The same exam was given to both groups. The mean scores were $76 \%$ and $89.2 \%$ for the traditionally educated group and computer-educated group, respectively. In addition, students reported that they felt higher levels of attentiveness, involvement, knowledge gained, attractiveness, and quality from the computerized seminar. In short, students believed that computer-based education was more engaging to the student.

Additional studies have attempted to identify improved methods of computer- and internet-based education. In a pre-clinical Fixed Prosthodontics course, Aragon and Zibrowski (2008) gave a hard-copy video presentation to a group of dental students prior to their first practical exam. The students proceeded to take three practical examinations during that year (PE1, PE2, and PE3), only the first of which was supplemented with take-home (ATAW) video presentations. The students' scores were also compared to the previous year's students who did not receive supplemental instruction for any of their practical exams. The students involved in the study scored better on the PE1 compared 
with the previous years class, and also scored better on PE1 than on their own subsequent clinical examinations (PE2, PE3). Of the 55 students involved in the study, 96\% of them reported that they benefited from the supplementary teaching material.

Hu et al. (2009) investigated the association between electronic media and dental student performance. Although their results demonstrate improvements in student performance only in select areas with the electronic education, they also make an important statement that there was no detriment in applying such education techniques. Even if the result was "no change in scores," electronic delivery is still a viable method of delivery.

Studies may not agree that video- and electronic-based education improves student outcomes, but educators across the globe are interested in the possibilities and research into the area has and continues to occur. One educational tool that has been used for many years, but has received little research attention is the use of mannequin-mounted typodont models for practicing dental procedures. There are many benefits to using nonpatient based practice simulations including increased safety in that it eliminates risk to live patients, all students from the same cohort practice the same clinical procedures under well-controlled conditions, and students can be evaluated fairly under the same conditions. Yet, a question of clinical equivalency exists. Nunez et al. (2012) investigated the correlation between dental students' clinical performance on mannequin-mounted typodonts and real patients. They enrolled 86 D4 dental students and asked them to complete mannequin-based testing and subsequent live-patient clinical testing for crown preparation proficiency. Their results indicate students' performance on typodont-based practice might not be reliably used to predict their performance on live patients. Students 
performed significantly worse in the live-patient clinical setting than on the mannequinmounted typodont. The human factors that seemed to play important roles in these findings include patients' physical and mental conditions and students' variable performance under pressure. With few alternatives available, mannequin-based practice is still a fundamental tool for dental education. However it must be realized that results from typodont-based research may not be generalizable to clinical situations. Further research is needed to accurately identify the association between mannequin-based practice and its clinical benefits.

At the time of writing this thesis, only two studies, both from the same researchers, have used non-patient, mannequin-based typodont practice to investigate the clinical efficiency and preference of inexperienced D2 dental students with digital scanning and material based impression methods. Using the iTero (Align Technology Inc, San Jose, CA, USA) chairside digital scanning system, Lee and Gallucci (2013) investigated the relative clinical efficiency (measured by the required treatment time, including preparation time, working time, retake/scan time $(\mathrm{m} / \mathrm{s})$, and the number of attempts) to achieve a clinically acceptable impression. They found that the digital scanning techniques were more efficient and associated with reduced preparation time and retake time. This research demonstrates the successful introduction of an digital scanning system into the dental student curriculum using mannequin-based typodont practice.

Lee et al. (2013) investigated the perception of difficulty and overall preferences between two groups of operators (students and experienced clinicians) performing digital scanning and material based implant impressions. Thirty D2 dental students with no prior experience and 30 dental practitioners with 5 years of clinical experience performed 
digital scans and material based impressions of a single implant model, and participants' perceptions of technique difficulty and preference were assessed using a visual analog scale (VAS). They found students preferred the digital scanning technique, whereas clinicians had no preference.

In summary, there is a dearth of evidence regarding the introduction and instructional methodology used to introduce chairside digital scanning technology into the dental curriculum. Current literature suggests that chairside digital scanning systems are well perceived by both patients and operators (both with and without experience), and that accuracy compared to materials based impression techniques is equivocal and, probably, system-specific. Instructional methods mostly include student experience with mannequin-based typodonts and stand-alone master models as methods of simulating patient conditions. Intuitively implementation will vary between institutions and depend on availability of impression technology, faculty and staff resources, and allocated education time.

\section{Significance of Current Study}

The proposed research will investigate the difference in DMD D2 students' perceptions and learning experiences using chairside digital scanning (3M ESPE, St. Paul, MN, USA) and polyvinyl siloxane (PVS) (3M ESPE, St. Paul, MN, USA) material based impression techniques after formal instruction and clinical simulations using mannequins. Attitudes will be determined by administering pre- and post-test questionnaires. Clinical efficiency during simulations will be determined by measuring clinical time required and number of attempts necessary to produce a clinically acceptable impression using both techniques. 
The results of this study have demonstrated recognition of the pedagogical need to incorporate training of this technology into dental school curricula by its subjects. This study also provides a precedent for measuring the efficiency of classroom education in this area. Practitioners and educators will be able to make use of this study to facilitate incorporation of this technology clinically. Finally, this research, through facilitating a change in dental education, will provide patients with a more comfortable experience and may excite those who have had negative experiences to give dentistry another chance.

The goal, as with all things in dentistry, is a healthier oral environment to support overall health. 
CHAPTER 3

HYPOTHESES

\section{Objectives}

The specific aims of this research project are:

1. To quantitatively measure and compare the differences in time (didactic video lecturing time and simulation laboratory demonstration time) required instructing D2 DMD students on the use of the material-based (polyvinyl siloxane [PVS]) dual-tray impression technique and chairside digital scanning technique (LAVA C.O.S (3M ESPE, St. Paul, MN, USA)).

2. To quantitatively measure and compare the differences in time (preparation and impression time) required for D2 DMD students to create clinically acceptable impressions using both a material-based (polyvinyl siloxane [PVS]) dual-tray impression technique and chairside digital scanning technique (LAVA C.O.S (3M ESPE, St. Paul, MN, USA)).

3. To determine the attitudes and beliefs of D2 DMD students on the current and future use of digital scanning technology, before and after instruction and clinical simulations exercises of both impression techniques 


\section{Null Hypothesis}

It is hypothesized that:

1. There will be no differences in time (didactic video lecturing time and simulation laboratory demonstration time) required to instruct D2 DMD students on the use of the material-based (polyvinyl siloxane [PVS]) dual-tray technique and chairside digital scanning technique (LAVA C.O.S (3M ESPE, St. Paul, MN, USA)).

2. There will be no difference in the total time required (preparation and impression time) for D2 DMD students to create clinically acceptable impressions using both a material-based (polyvinyl siloxane [PVS]) dual-tray technique and chairside digital scanning technique (LAVA C.O.S (3M ESPE, St. Paul, MN, USA)).

3. There will be no difference in the perception and expectation of current ULSD students for the current and future use of digital scanning technology, before and after the exposure of instruction of both impression techniques and students' exercises. 


\section{CHAPTER 4}

\section{MATERIALS AND METHODS}

\section{Overall Research Design}

There are two aspects to this research:

1. Pre- and Post-Instructional Knowledge, Attitude and Beliefs of D2 DMD

Students. This component was a single group Pre-test / Post-test design based on the administration of two questionnaires with identical questions separated by an intervention (didactic and laboratory instruction and student simulation exercise). The goal of such a research design is to analyze the difference in responses due to the intervention. The design included a pre-exposure questionnaire (Appendix B) featuring questions exploring participants' perceptions of, and familiarity with, digital scanning and material based impression techniques. The questionnaire also captured some demographic information. A post-exposure questionnaire was also recorded and discrepancies in responses compared.

2. Timed Clinical Efficiency. Following the questionnaire, participants watched a video lecture on material based PVS impression technique, observed an investigator-led demonstration and then performed impressions using polyvinylsiloxane (PVS). Later students watched a video lecture on digital 
scanning techniques, observed an investigator-led demonstration and then performed impressions using a chairside digital scanner (LAVA COS). Both simulations were performed until a clinically acceptable impression was achieved as approved by an investigator using a standardized checklist (Appendix C - Clinical Acceptability Forms). The time for each step was evaluated for differences in instructional time and clinical efficiency.

\section{Subject Recruitment}

The investigation was marked "Exempt" by the Institutional Review Board (IRB) at the University of Louisville School of Dentistry (Louisville, KY) on June 18, 2013 (IRB \# 13.0242). Participants were then recruited vie email as approved by the IRB. The email detailed the department conducting the investigation, the need for research participants, stated the purpose of the study, and included some general inclusion criteria. In order to qualify, potential participants were required to meet the following criteria:

1. Inclusion Criteria

a. Must be a dental student enrolled in the school of dentistry

b. Must be at least 18 years of age

c. Must be willing to commit to taking required lectures and laboratory demonstrations and completing a clinically acceptable impression with up to 2 different impression methods.

d. Understands and has signed informed consent.

e. Must commit to not discussing or seeking outside education on the technology being studied over the period of the study except for coursework presented to students by their instructors as part of their natural course of study.

2. Exclusion Criteria 
a. Inability to commit to taking lectures and laboratory demonstrations, and completing a clinically acceptable impression with up to 2 different impression methods.

b. Inability to sign informed consent.

c. Prior clinical experience for conventional PVS/polyether and any digital impression procedures.

When a qualifying participant was identified, the primary investigator (PI) explained to them the Informed Consent Form (ICF) so that they may consider their participation. Once they had agreed to participate, participants were scheduled by the PI to accommodate instructor and student schedules.

On the first day of their participation, the PI went over the ICF with the subject again, at which time they signed the document. The subject was then given a Subject ID\# which would be used to anonymously codify the subject's data sheets and questionnaire responses for the duration of the investigation. The subject's name and Subject ID\# were recorded on a key that would be kept under lock and key to maintain confidentiality.

\section{Questionnaire Administration}

Two questionnaires were administered to the D2 DMD students.

\section{Pre-Instruction (Intervention) Questionnaire}

Initially subjects completed a fourteen-item questionnaire. The questionnaire comprised, 3 domains: A. Demographic Information, B. Subject's existing familiarity with impression techniques (Answers ranging from "Very Unfamiliar $=1$ " to "Very Familiar $=5 "$ '), and C. Expected perceived ease of use and future predictions (Answers ranging from "Very Difficult $=1$ " to "Very Easy $=5$ ). The subject ID\# and the date were 
also recorded in the upper right hand corner of the questionnaire. The exercise consisted of a combination of multiple choice, yes/no, and Likert scale questions (from 1-5) (Appendix B).

\section{Post-Instruction (Post-Intervention) Questionnaire}

The Post-Exposure questionnaire consisted of 10 questions and an open-ended question that allowed participants to express, in their own words, how their experience with chairside digital scanning technology affected their views on it's potential usefulness for the future. All questions were matched to questions of the domain C in the PreExposure Questionnaire so that changes in opinions/thoughts due to the intervention could be measured (Appendix C)

\section{Instruction}

\section{Didactic Presentations}

Material Based Impression Technique

Following the Pre-Exposure Questionnaire, subjects watched a video lecture on PVS impressions. The PVS instructional video was recorded by Dr. Stephen Mattingly of the ULSD Department of General Dentistry and Oral Medicine, and modified by the PI to correspond to the clinical exercise. The duration of the instructional video was 9:39min. This video lecture described the steps necessary for taking an impression with PVS material using a triple tray, beginning with a description of required armamentaria and finishing with removal of the impression tray from the mannequin-based dentoform. Following the video, participants were encouraged to ask questions before heading to the 
clinic. The measured time for the classroom education began with the start of the video and was terminated when the subject no longer had any questions regarding the video or the upcoming exercise.

\section{Digital Scanning Technique}

Once subjects completed their entire experience with the PVS impression technique they returned to the classroom the same day, or another day shortly thereafter, to begin their instruction with the digital scanning technique. This video lecture was created by Dr. Lin, Co-PI. The duration of the instructional video was 15:12min. This video lecture described the steps necessary for taking an impression with LAVA C.O.S

(3M ESPE, St. Paul, MN, USA) digital scanning system, beginning with a description of basic operation of the digital system and finishing with the scanning protocol to complete a quadrant impression with opposing dentition and inter-occlusal record. Following the video, subjects were encouraged to ask questions before the corresponding clinical exercise. The measured time for the classroom instruction began with the start of the video and was stopped when the participant no longer had any questions regarding the video or the upcoming exercise.

\section{Investigator-Led Demonstrations}

\section{Material Based Impression Technique}

In the simulation laboratory, a mannequin was a set-up with a dentoform containing a full coverage metal crown preparation on tooth \#30 and the necessary armamentarium for a triple-tray impression. The PI started the timer and demonstrated the PVS impression technique using a triple tray as described in the video. Subjects were 
encouraged to ask questions during this demonstration so that questions could be addressed by the PI with armamentarium in-hand for proper demonstration. The stopwatch was ended when the subject no longer had any questions regarding this exercise and the PI had completed his demonstration.

Digital Scanning Technique

For the digital scanning demonstration, the same mannequin and dentoform were set-up and the LAVA C.O.S (3M ESPE, St. Paul, MN, USA) was turned 'on' and placed into the 'practice' mode. This mode allows the user to use the full scanning and review capabilities of the machine, without providing patient data. The PI started the timer and demonstrated the digital impression technique as described in the video. Subjects were encouraged to ask questions during this demonstration so that questions may be answered by the PI with the scanner at hand for proper demonstration. The stopwatch was stopped when the subject no longer had any questions regarding this exercise and the PI had completed his demonstration.

\section{Impressions}

\section{Material Based Impressions}

The lot number and expiration date for each tube of heavy-body PVS, light-body PVS, and adhesive was recorded prior to beginning the exercise (Appendix A). Following the investigator-led demonstration, the subject was allowed to begin their first attempt at taking an impression with PVS. The timer was started as the student began handling the armamentarium. The PI did not initiate conversation with the participant unless the participant chose to converse casually as one might do with a patient while preparing for 
an impression; and the PI did not answer questions regarding the impression technique itself unless the student left the cubicle as if they were consulting a supervising faculty in a neighboring cubicle. All decisions regarding proper sequence and timing were left up to the participant.

When the participant finished their impression and brought it to the PI, the timer was 'paused' in case there was need for further clinical intervention to achieve a clinically acceptable PVS impression. The PI then examined the impression and graded the impression for clinical acceptability using criteria derived from those used in the ULSD clinic. Each participant has a clinical acceptability sheet with grades marked. A sample Clinical Acceptability Form can be found in Appendix D. If an impression was deemed 'clinically unacceptable,' the participant was shown the critical error and instructed to make another impression. The stopwatch was restarted when the student re-entered the cubicle. When a 'clinically acceptable' impression was shown to the PI, the level of acceptability was marked for each criteria on the clinical grading sheet and the stopwatch time was recorded. At this time the student either went back to the classroom for the lecture on digital impressions or went on with their academic responsibilities and returned the following day to complete their participation.

\section{Digital Scans}

Following the demonstration of the digital impression system by the PI, each participant began his/her own digital impression. If a student wanted to ask a question regarding the sequence for scanning, or other matters related to the task of making a digital impression, they were asked to leave the cubicle to ask the question, once again to simulate consulting a supervising faculty. When the participant had completed their 
impression and notified the PI, the timer was stopped. At this point the PI entered the cubicle and checked the digital impression. If there were critical errors the participant was notified and a suggestion was made for how to access the missing segments with the scanning wand. The stopwatch was restarted when the participant picked up the scanning wand. The criteria for a clinically acceptable impression were derived from the form used for PVS impression evaluation.

\section{Statistics}

The mean and standard deviation was calculated for time parameter measured. These means were related using the dependent t-test to compare the instruction and clinical exercise times of participants for the different impression techniques. Bonferroni correction was used to control the familywise error rate for 6 dependent t-tests. The desired significance level for the whole family of dependent t-tests was set at $\alpha=.05$. With the Bonferroni correction, each individual hypothesis was tested at $\alpha=.05 / 6$ $=.0083$ level.

Mean ranks and standard deviations were calculated from responses to questions relating to pre- and post-instruction existing familiarity, ease of use level, and attitudes and beliefs regarding the impression techniques. Wilcoxon Signed-Ranks test was used to relate these values to one another and to identify statistically significant results. Bonferroni correction was used to control the familywise error rate for 5 subsequent tests. The desired significance level for the whole family of Wilcoxon Signed-Ranks tests was set at $\alpha=.05$. With the Bonferroni correction, each individual hypothesis was tested at $\alpha$ $=.05 / 5=.01$ level. The Wilcoxon Signed-Rank test was used as the responses to 
questions represented ordinal data and there was no expectation for the responses to be parametric. 


\section{CHAPTER 5}

\section{RESULTS}

\section{Pre- and Post-Intervention Questionnaires}

Results from questions in Domains A and B relating to subject demographics in were not compared. In Domain C, numerous comparisons between pre- and postintervention attitudes and beliefs were possible. For those questions where it was relevant, such comparisons were made.

\section{Subject Demographics}

The majority of subjects did not have relevant prior dental experience, defined as a volunteer or paid position requiring regular attendance in a dental office. The explanation was intended to exclude shadowing and observation opportunities. Most of the participants intended to pursue a career in the private practice as general practitioners, including those committed to joining a branch of the military without any expectation to pursue specialty training. Table 1 shows subjects' mean age as well as their responses regarding experience and future expectations. 
Table 1: Demographic information

\begin{tabular}{ccccc}
\hline Participants' Age & \multicolumn{3}{c}{$25 \pm 2.31$ yrs. } \\
Previous Dental & \multicolumn{2}{c}{ Yes $(20 \%)$} & \multicolumn{2}{c}{ No $(80 \%)$} \\
Experience & Private Practitioner & AEGD/GPR & OMFS & Undecided \\
Immediate Plan & $(60 \%)$ & $(20 \%)$ & $(16 \%)$ & $(4 \%)$ \\
After Graduation & $(60 \%)$ & & \\
\hline
\end{tabular}

\section{Efficiency Outcomes}

\section{Total Teaching Time: Video Lecturing Time and Instructor-Led Demonstration Time}

Figure 1 is a boxplot comparison of the teaching time required for both impression techniques. Both plots were divided into time spent explaining the respective impression technique via video lecture (Video Lecturing Time) and time spent demonstrating that technique in person (Instructor-Led Demonstration Time). There was a statistically significant increase $(t=-16.714, \mathrm{p}=0.000)$ in time spent teaching digital scanning $(1507.78$ $\pm 142 \mathrm{sec})$ versus time spent teaching PVS impressions $(887.43 \pm 108 \mathrm{sec})$. Video lectures required an increase in education time $(\mathrm{t}=-30.664, \mathrm{p}=0.0000)$ for digital scanning $(957.75 \pm 51 \mathrm{sec})$ compared with PVS impressions $(604.17 \pm 23 \mathrm{sec})$. This was also true for Instructor-Led Demonstration Times $(\mathrm{t}=-7.571, \mathrm{p}=0.0000)$ when comparing digital scanning (543.35 $\pm 130 \mathrm{sec})$ and PVS impressions $(282.26 \pm 102 \mathrm{sec})$.

Figure 1. Teaching Time (Comparison of mean teaching times for video and lecturebased learning of digital scanning and PVS impression techniques, in sec) 


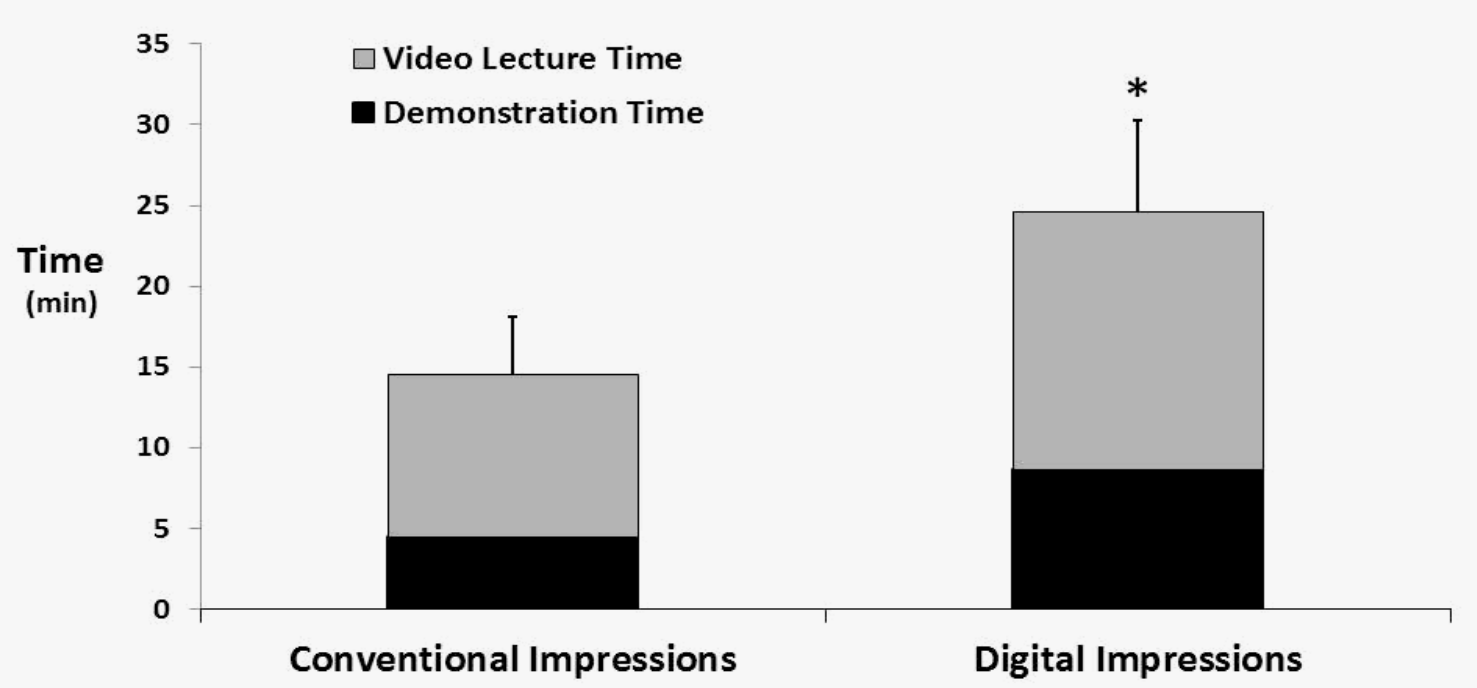

\section{Execution Time: Preparation Time and Impression/Scan Time}

Figure 2 is a boxplot comparing the time spent by participants performing each impression technique. The plots were divided into time spent preparing the impression (Preparation Time) and time spent executing the impression (Impression/Scan Time). There was a significant increase $(\mathrm{t}=-4.493, \mathrm{p}=0.0000)$ in total time spent executing digital scanning $(1222.29 \pm 214 \mathrm{sec})$ versus PVS impressions $(886.38 \pm 297 \mathrm{sec})$ despite a reduction in preparation time. Digital scanning took less $(\mathrm{t}=5.562, \mathrm{p}=0.0000)$ time to prepare for impressing $(126.17 \pm 52 \mathrm{sec})$ compared to PVS $(383.43 \pm 216 \mathrm{sec})$. Preparation time for PVS impressions included: time spent assembling the dispensing gun, applying adhesive to the triple tray, and positioning the patient. Preparation time for digital scanning included: time spent powdering the dentition, entering appropriate scan modes, and positioning of the patient. Other actions between these steps were assumed. Digital scanning took a significantly longer $(\mathrm{t}=-11.163, \mathrm{p}=0.0000)$ time to actually make the impression (scan) $(1090.39 \pm 202 \mathrm{sec})$ as compared with PVS 
impressions $(515.52 \pm 142 \mathrm{sec})$. Impression time for PVS impressions began with application of light body to the abutment tooth. Scan time for digital impressions began with activation of the scan wand.

Figure 2. Execution Time (Comparison of mean execution times for video and lecturebased learning of digital scanning and PVS impression techniques, in sec)

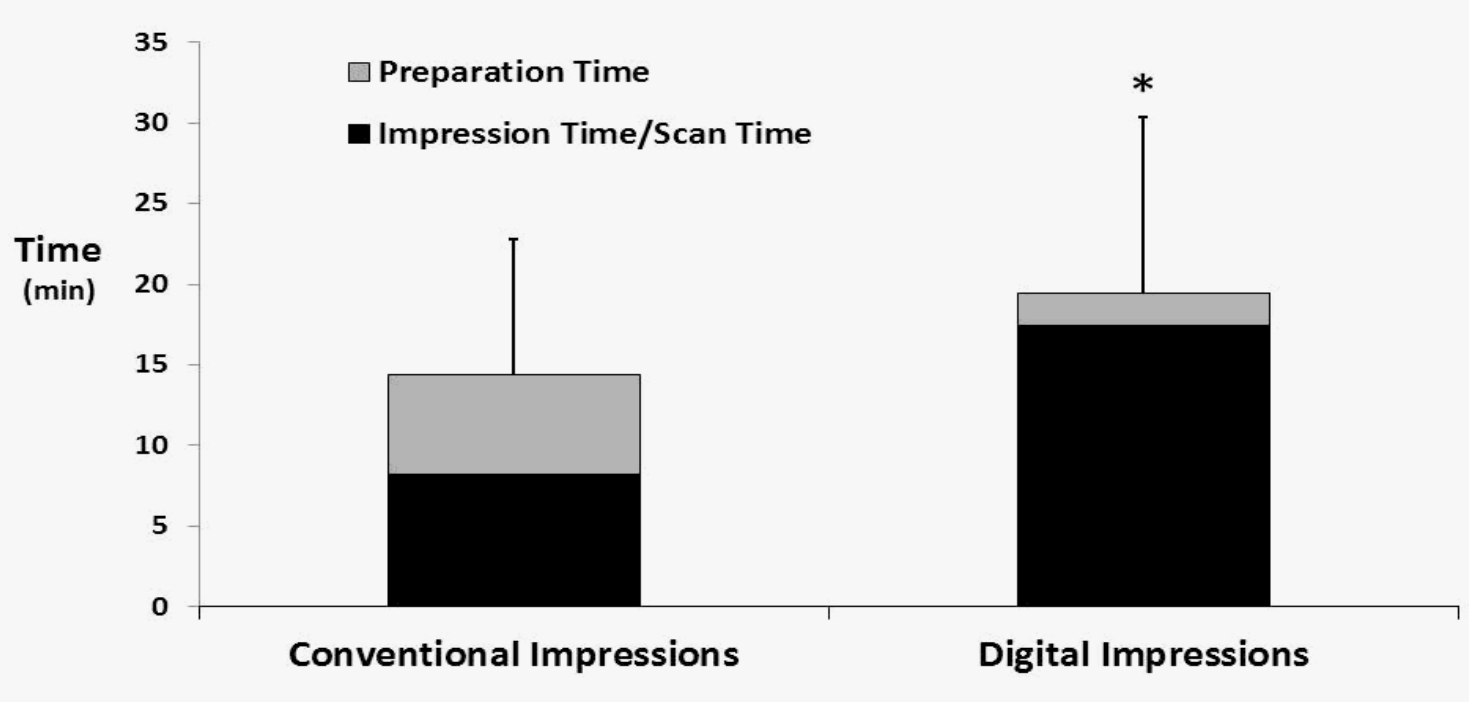

Table 2 summarizes the means, standard deviations and t-test results comparing time spent during teaching (video lecture and time spent during investigator-led demonstrations were combined as Total Teaching Time), and execution (preparation time and impression time were combined as Total Execution time) between the two impression modalities. A significant difference was noted between the two impression modalities as a whole, and for each step in the process. The only timed measurement that was less for the digital scanning method was Preparation Time. The difference was still statistically significant. 
Table 2: Efficiency outcomes measured in Seconds (Summary of values depicted in Figure 1 and Figure 2, Mean $\pm \mathrm{SD}$, in sec)

\begin{tabular}{cccc}
\hline & Conventional & Digital & P value \\
\hline Instructional Time & & & \\
Video Lecture Times (s) & $604.17 \pm 23.28$ & $956.75 \pm 51.30$ & $.0000^{*}$ \\
Demonstration Times & $282.26 \pm 101.88$ & $543.35 \pm 130.30$ & $.0000^{*}$ \\
TOTAL & $887.43 \pm 107.91$ & $1507.8 \pm 141.56$ & $.0000^{*}$ \\
Clinical Exercise & & & \\
Preparation Times & $383.43 \pm 215.54$ & $126.17 \pm 52.44$ & $.0000^{*}$ \\
Impression Times & $515.52 \pm 142.06$ & $1090.4 \pm 202.03$ & $.0000^{*}$ \\
TOTAL & $886.38 \pm 297.09$ & $1222.3 \pm 214.18$ & $.0000 *$ \\
\hline
\end{tabular}

* Statistical significance $P<\alpha=.0083$

\section{Existing Familiarity, Perceived Ease of Use Level and Future Expectations \\ Existing familiarity}

Figure 3 shows participants' reported proficiencies with chairside digital scanning technology to help analyze possible reasons for participant preferences. Participants generally considered themselves familiar with computers and digital devices. This was not unexpected, as the average age of participants was 25 years of age (Table 1). Figure 3 also shows existing familiarities (Mann-Whitney 901.00, $\mathrm{p}=0.0000$ ) with conventional (PVS) impression techniques $(3.96 \pm 0.61)$ and chairside digital scanning techniques $(1.96 \pm 1.06)$. These results are seen in Table 3.

Figure 3. Existing Familiarity with Technology and Impression Techniques 


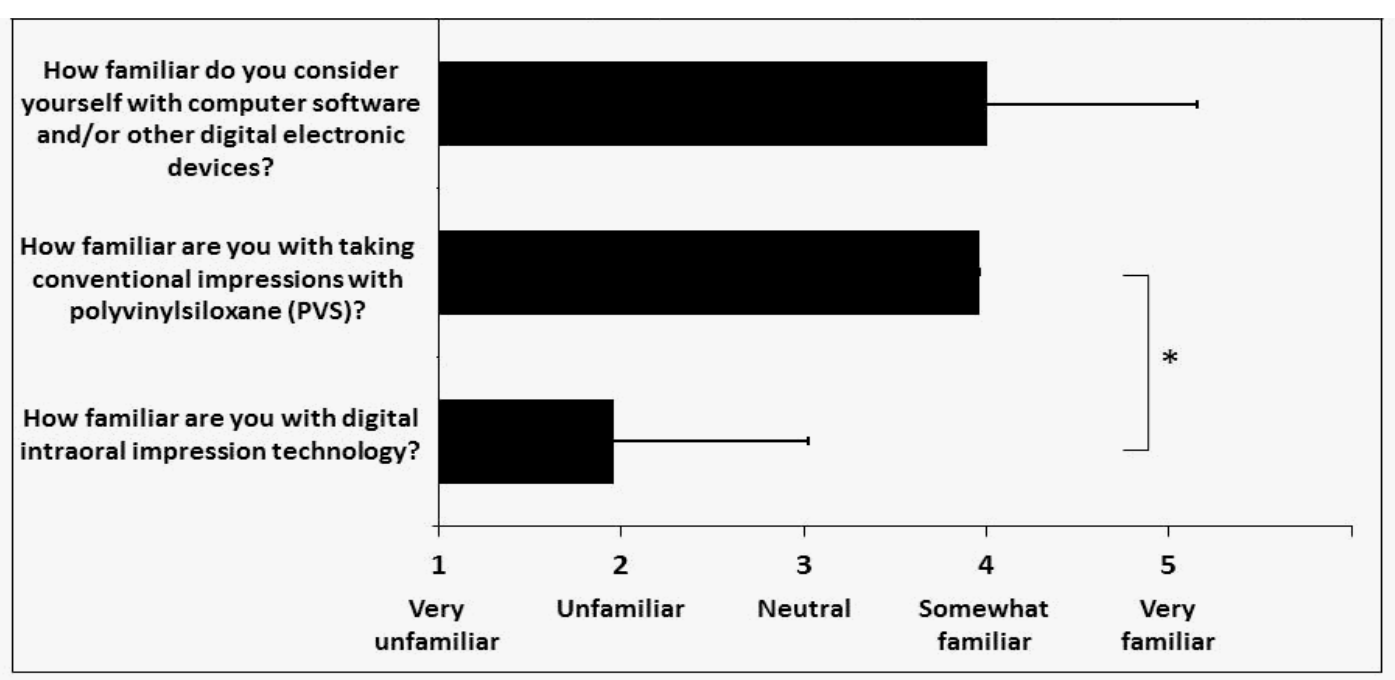

Table 3. Participants' existing familiarity with impression techniques (All data are presented as mean $\pm \mathrm{SD}$, and median in parentheses)

\begin{tabular}{cc|c|c}
\hline & Conventional & Digital & $P$ value \\
\hline $\begin{array}{c}\text { Existing familiarity } \\
\text { Pre-Exposure }\end{array}$ & $3.96 \pm 0.61(4)$ & $1.96 \pm 1.06(2)$ & $.0000 *$ \\
\hline
\end{tabular}

* Statistical significance $\mathrm{P}<\alpha=.01$

\section{Perceived Ease of Use Level Help}

Figure 4 compares pre-exposure to post-exposure of questionnaire responses and in regard to participants' expected and experienced ease of use for each impression technique. In the pre-survey participants failed to demonstrate a difference (MannWhitney $574.00, \mathrm{p}=0.1914)$ in expectation for the digital scanning technique $(3.84 \pm$ $0.85)$ to be easier to execute over the conventional impression $(3.52 \pm 0.77)$. Results lacked statistical significance $(p=.106, \mathrm{P}>\alpha=0.0083)$. After experiencing both impression techniques the responses were reversed (3.56 \pm 0.96 for scanning, $4.08 \pm 0.57$ for PVS), however, the difference was not statistically significant $(p=.03)$. These values 
can be seen in Table 4, comparing expectations and experiences of one technology against the other.

Figure 4. Perceived Ease of Use Level

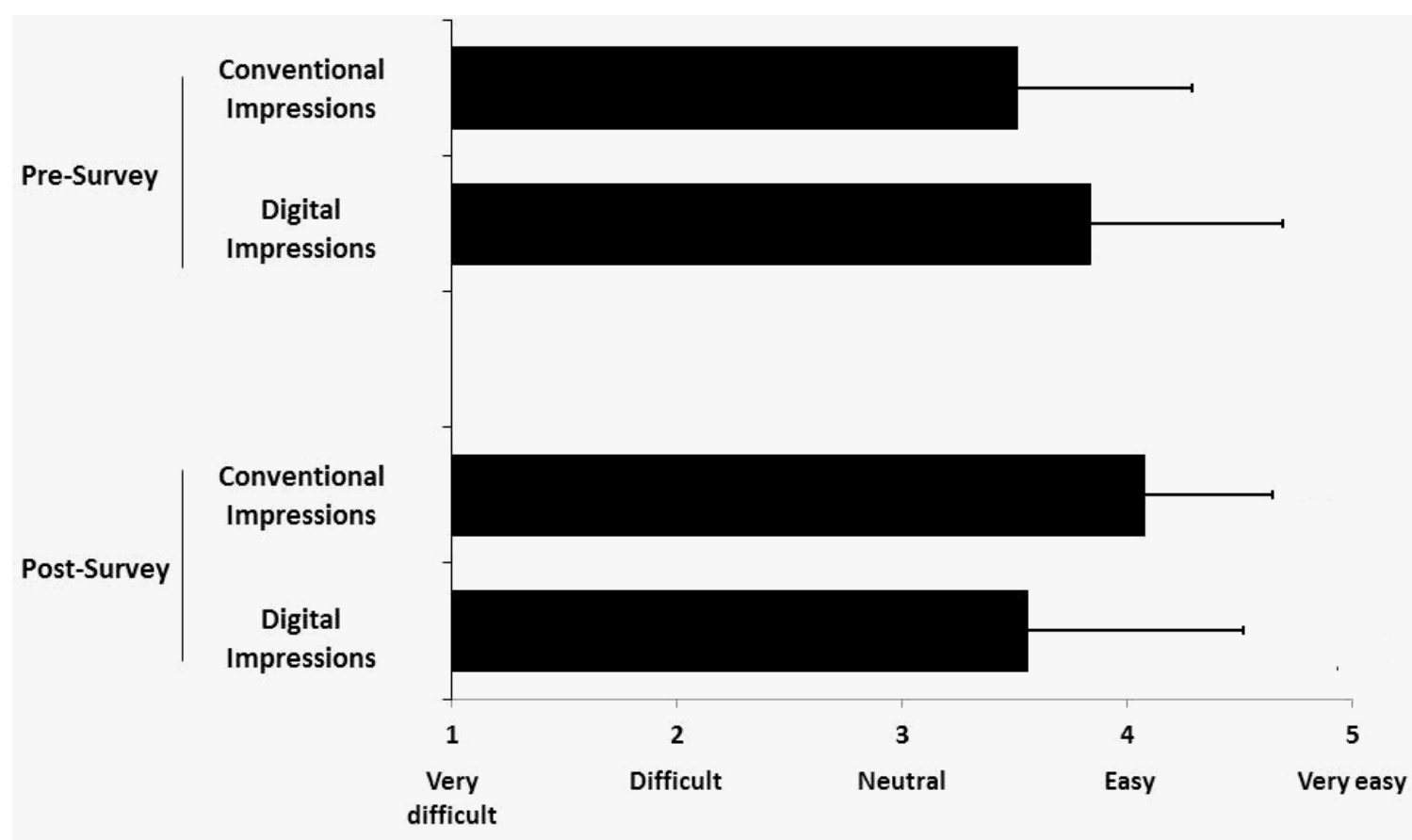

Table 4: Perceived Ease of Use Level between two Impression Techniques

\begin{tabular}{c|c|c|c}
\hline & Conventional & Digital & $P$ value \\
\hline Perceived Ease of Use & & & \\
Pre-Exposure & $3.52 \pm 0.77(4)$ & $3.84 \pm 0.85(4)$ & .106 \\
Post-Exposure & $4.08 \pm 0.57(4)$ & $3.56 \pm 0.96(4)$ & .03 \\
\hline
\end{tabular}

All data are presented as mean $\pm \mathrm{SD}$, and median in parentheses.

Tables 5 compared expectations before exposure with resulting experience after exposure, independently, for each impression modality. It can be seen from Table 5 that 
making a conventional impression proved significantly easier than expected $(p=.002)$. While the digital impression technique did not show statistically significant difference before and after exposure in student's perceived ease of use level $(p=.016)$.

Table 5: Student's Perceived Ease of Use Level before and after exposure

\begin{tabular}{c|c|c|c}
\hline & Pre-Exposure & Post-Exposure & $P$ value \\
\hline Perceived Ease of Use & & & \\
Conventional & $3.52 \pm 0.77(4)$ & $4.08 \pm 0.57(4)$ & $.002 *$ \\
Digital & $3.84 \pm 0.85(4)$ & $3.56 \pm 0.96(4)$ & .106 \\
\hline
\end{tabular}

All data are presented as mean $\pm \mathrm{SD}$, and median in parentheses.

Answers ranging from "Very Difficult $=1$ " to "Very Easy = 5".

* Statistical significance $P<\alpha=.01$

\section{Future Expectations}

Figure 5 shows participants' expectations before and after exposure to a chairside digital scanning system. No inferential statistics were calculated for these responses.

The first question asked for expected number attempts needed to attain competency with digital impression technique. Initially participants expected an average of 5.52 attempts to attain competency. After trying the digital impression, the average response dropped to 3.9 .

The next two questions relate participants' perceptions regarding efficiency in time and cost as they relate to making impressions with both techniques. The digital impression technique was the most frequent response for savings in both areas, both 
before and after exposure to the digital impression. Of note, few participants selected PVS impressions as a means of saving either money or time, considerably more were undecided.

The final three questions show participants' expectations for their personal futures with chairside digital scanning. $76 \%$ expect to have an digital scanner in their at their first job, and $92 \%$ of them expected a digital scanner to become their primary impression technique at some point during their professional careers. The final question was only in the post-exposure questionnaire and asks if the participant experienced a change in opinion regarding digital impressions associated with learning about the technology. $72 \%$ expressed a positive change in opinion regarding digital scanning following exposure; the remaining $28 \%$ stated no change in their opinion. $0 \%$ said their opinion of digital scanning worsened due to their exposure to the technology. 
Figure 5. Current and Future Expectations (unless otherwise specified, numeric values are total responses, in parentheses are the percent of all responses)

\begin{tabular}{|c|c|c|c|c|c|c|}
\hline & \multicolumn{3}{|c|}{ Pre-Survey } & \multicolumn{3}{|c|}{ Post-Survey } \\
\hline $\begin{array}{l}\text { How many impressions do you think you will } \\
\text { need to take before you feel comfortable and } \\
\text { competent enough to use a digital scanner on a } \\
\text { live patient in the clinic? }\end{array}$ & \multicolumn{3}{|c|}{$\begin{array}{c}\text { Mean: } 5.52 \\
\text { SD: } 6.39 \\
n=25\end{array}$} & \multicolumn{3}{|c|}{$\begin{array}{c}\text { Mean: } 3.9 \\
\text { SD: } 3.09 \\
n=25\end{array}$} \\
\hline $\begin{array}{l}\text { With experience, what technique do you } \\
\text { expect would save you the most time in your } \\
\text { dental office? }\end{array}$ & $\begin{array}{l}\text { Conventional } \\
\qquad 0(0 \%)\end{array}$ & $\begin{array}{l}\text { Digital } \\
18(72 \%)\end{array}$ & $\begin{array}{l}\text { Undecided } \\
7(28 \%)\end{array}$ & $\begin{array}{l}\text { Conventional } \\
\qquad 2(8 \%)\end{array}$ & $\begin{array}{l}\text { Digital } \\
16(64 \%)\end{array}$ & $\begin{array}{l}\text { Undecided } \\
7(28 \%)\end{array}$ \\
\hline $\begin{array}{l}\text { With experience, what technique do you } \\
\text { expect would save you the most money in your } \\
\text { dental office? }\end{array}$ & $\begin{array}{l}\text { Conventional } \\
\qquad 3(12 \%)\end{array}$ & $\begin{array}{l}\text { Digital } \\
14(56 \%)\end{array}$ & $\begin{array}{l}\text { Undecided } \\
8(32 \%)\end{array}$ & $\begin{array}{l}\text { Conventional } \\
\qquad 1(4 \%)\end{array}$ & $\begin{array}{l}\text { Digital } \\
17(68 \%)\end{array}$ & $\begin{array}{l}\text { Undecided } \\
7(28 \%)\end{array}$ \\
\hline $\begin{array}{l}\text { Do you expect to have a digital scanner } \\
\text { available to you in your first job as a dental } \\
\text { professional? }\end{array}$ & $\begin{array}{c}\text { Yes } \\
19(76 \%)\end{array}$ & & $\begin{array}{c}\text { No } \\
6(24 \%)\end{array}$ & $16(64 \%$ & & $\begin{array}{c}\text { No } \\
9(36 \%)\end{array}$ \\
\hline $\begin{array}{l}\text { Do you expect to use a digital scanner as your } \\
\text { primary impression technique at some point in } \\
\text { your career? }\end{array}$ & $\begin{array}{c}\text { Yes } \\
23(92 \%)\end{array}$ & & $\begin{array}{c}\text { No } \\
2(8 \%)\end{array}$ & Yes & & $\begin{array}{c}\text { No } \\
1(4 \%)\end{array}$ \\
\hline $\begin{array}{l}\text { How has learning about digital impression } \\
\text { changed your opinion regarding the usefulness } \\
\text { of this technology? }\end{array}$ & & N/A & & $\begin{array}{l}\text { Improved } \\
18(72 \%)\end{array}$ & $\begin{array}{l}\text { Unchanged } \\
7(28 \%)\end{array}$ & $\begin{array}{c}\text { Worsened } \\
0(0 \%)\end{array}$ \\
\hline
\end{tabular}




\section{CHAPTER 6}

\section{DISCUSSION}

Digitization of workflow in restorative dentistry has improved the efficiency of patient treatment. Dentists can now accomplish restorative results with the same level of accuracy more efficiently and with less discomfort. Efficiency reductions can be attributed to decreased number of patient visits, reduced time per visit and, and a decrease in steps needed to accomplish a satisfactory restorative result (Joda and Bragger, 2014, and Lin et al. 2014). The use and acceptance of CAD/CAM technology for restorative dentistry has increased in recent years as improvements in accuracy of digital scanners and improvements in communication between dental offices and dental laboratories have made workflow more effective. CAD/CAM, CBCT, and other digital technologies can now be used to produce "all-digital" workflows for implant and complex restorative cases (Patel 2010).

The aim of this study was to determine the factors associated with the incorporation of chairside digital scanning technology into a dental curriculum. The specific purpose of this investigation was two-fold: 1) To compare the time required to instruct students in the use of conventional and digital impression methods for singlecrown restorations and 2) Investigate students' expectations and perceptions for digital scanning technology before and after instruction in both methods. 
We found that significantly more time is required to provide instruction in digital scanning than material based impression techniques. We also found that participants had high expectations for digital impression technology before exposure; and their expectations generally improved as a result of their experiences with the digital scanner.

Second-year (D2) dental students were recruited for this study because they lacked clinical and laboratory experience taking PVS impressions. One possible potential bias in selecting this convenience sample was that they had prior experience with alginate impression technique. This impression technique is similar to PVS technique in many ways. Variations between the two techniques include use of the PVS dispensing gun and auger tip as opposed to a bowl and spatula, as well as the use of light body material placed directly into the mouth in the areas of particular concern. D2 students were also selected rather than other years for scheduling considerations, although D1 students could be incorporated in future studies.

This study was executed on typodont mannequins to reduce confounding variables and to simulate the education process for preclinical fixed prosthodontics. The mannequins were positioned upright so that positioning of the mannequin head would be up to the student. Patient positioning plays an important role in both impression techniques. A pre-prepared single-tooth abutment was chosen, as this is a universal experience encountered by dental students and practitioners alike. Triple trays were used because it is the same technique used for single crowns in students' preclinical courses and it also makes comparison with digital impressions easy because a similar amount of clinical information can be obtained from both techniques. 
The LAVA C.O.S. (3M ESPE, St. Paul, MN, USA) chairside digital scanning system was used because it was available at our institution. The iTero (Align Technology Inc, San Jose, CA, USA) would have been a good comparison because the two systems represent varying image capture technologies. The 3M LAVA (3M ESPE) acquires data through continuous video and uses a titanium dioxide powder to enhance data capture. The iTero (Align Technology) does not require the use of powder for image capture and acquires data through multiple still images taken by the operator as prompted by the iTero software. Currently available digital scanning systems fall into one of two categories; continuous video and still image capture, as represented by the two systems above. Additional research comparing the two would help more thoroughly define the nature of operators' preferences.

A benefit to using the LAVA C.O.S. (3M ESPE) is the availability of a practice scan mode that allows the operator to scan without being prompted to fill out a laboratory prescription or input patient information. A difficulty associated with the use of this system is the positioning of the camera within the wand. The wide-angle camera lens is right at the surface of the wand-tip, requiring the operatory to maintain, freehand, an optimal distance between 5 and $15 \mathrm{~mm}$ from the surface to be captured. By comparison, the iTero (Align Technology) camera is inset and allows the operator to rest the wand against the surface to be scanned without disrupting data capture. 3M ESPE has responded with a removable cage to be placed over the wand tip to allow the wand to rest during scanning. While the requirement to suspend the wand tip may be viewed as a disadvantage to some, it also allows for more freedom of movement, which provides two advantages. First, combined with continuous video, data acquisition can become as fast 
as the operator is able to maneuver the wand tip around the dentition of interest. Resting the wand-tip is likely to slow down the advanced operator. Second, the freedom of movement is convenient when acquiring data in hard to reach areas, such as interproximal surfaces and subgingival margins, where the camera needs to come closer to the teeth in order to enter the target area into the camera's depth of field.

Polyvinylsiloxane was chosen as the conventional impression material because it has proven dimensional stability and was readily available. Alternative options would include varying types of reversible and irreversible hydrocolloid materials.

Use of video-lecture has been established as an effective means of dental education. A benefit of video lectures is the standardization of each student's educational exposure. The lectures in this study were demonstrated on a laptop in a quiet room, free of distractions. The video lecture for the PVS method was shorter than the video lecture for the digital method, and accounted for the majority of the difference between the education-times of the two impressions methods (Table 2). This is partially due to the more technically complex nature of the digital technique. The armamentarium for PVS impressions is based on simple physical principles, while software used with digital systems is designed with advanced capabilities such as 3-Dimensional viewing, multiaxis image rotation, etc.

Following each video lecture participants were encouraged to ask questions. A higher number of questions relating to use of the digital system contributed to the increase in education time. Many participants expressed a desire to ask additional questions during the demonstration; as the software prompts were difficult to visualize 
before becoming familiar with the display unit. It would seem the increase in education time due to questions was due difficulty imagining the more complex digital system. Instructor-led demonstrations were carried-out by the same investigator for consistency. A strict script was not used because it would not allow for the openexchange between student and professor as the exercise was intended to simulate, although an effort was made to cover the same points. This also allowed the investigator to cater the tone and pace of the demonstration based on the participant's demonstrated understanding.

Demonstration times were higher for the chairside digital scanning method. First, participants were not entirely naive to the conventional impression based on their previous experience with alginate. Many participants cited this prior experience as the reason they expected to make an impression quicker with the conventional method. Second, as mentioned above, the number of questions asked during the demonstration of the digital method was greater. Third, the increased innate complexity of the digital system required a longer demonstration.

The total time spent teaching was calculated as the combination of time for video lectures and instructor-led demonstrations for each impression modality. The significance of these results, and the ones described previously, is the generally increased amount of time required to educate students on the use of chairside digital scanning systems. These results should be applied to designing dental school curricula with the understanding that results will vary with each institution. Schools will have to set their own curriculum based on their number of students, digital scanners available and allotted time in clinical simulation areas. The understanding that has been gained is the knowledge that educating 
students in the use of digital impression systems will take longer than it will for conventional impression methods. This difference will be unique for each institution based on their experiences. These experiences should be shared between dental schools so that each can benefit from the experiences of the other. Further research is needed to demonstrate preferred methods for teaching digital impressions.

The impressions performed by participants were timed and evaluated based on the criteria in the clinical acceptability forms (Appendix C). Their participation times were divided into preparation time and impression time. The idea was to isolate the preparation, which for the digital impressions would only have to be performed once at the beginning of their execution. If a digital impression was inadequate, the scanning could simply be resumed without further preparation. In a conventional impression, the preparation time would have to be repeated if the impression was not satisfactory.

An unanticipated issue with this organization was that investigators were not prepared to accurately record the times during which additional powder was applied. Therefore, additional time spent preparing teeth during the digital scanning was lost in the execution time measurements. It should be noted time needed to spot-add powder is small and unlikely to significantly alter participants' times. The need to apply additional powder resulted from operator's fingers removing powder while stabilizing the wand. Many also applied additional powder to individual cusps when the scanning wand had difficulty acquiring sufficient data. This additional time is unlikely to have affected the results given the average time spent preparing for PVS impressions was more than three minutes longer than time spent preparing for digital impressions. 
Preparation time was separated from execution time also because there is a difference in gains-available from experience for one than the other. With experience, operators are likely to drastically reduce time spent scanning while time spent preparing the teeth with powder provides little room for improvement. A conventional impression, by comparison, has little room for improvement in efficiency making the impression because the operator is bound by the setting time of the impression material. This suggests, despite the inexperienced operator spending more time making a digital impression (Table 2), the area where most of that time was spent is also the area where most potential for improvement exists.

The impression material used in this study, Aquasil Ultra XLV, regular set, and Aquasil Ultra Heavy, regular set, (Dentsply) carry a manufacturer's recommendation five minutes setting time. This includes time for the light body to be positioned over areas of interest, $1 \mathrm{~min} 10 \mathrm{sec}$, and an additional $2 \mathrm{~min} 30 \mathrm{sec}$ before the heavy body should be in place, per manufacturer recommendations. It should be noted that regular set PVS is used at the dental school because students are entry-level clinicians. With experience, clinicians may opt to use the fast set PVS, which carries a manufacturer's recommendation of 3 minutes setting time. Operators may remove the impression sooner at their own discretion, at the risk of distorting or otherwise disrupting the integrity of the dental arch capture. Inexperienced operators, as this study suggests, erred on the side of safety in an effort to ensure the clinical acceptability of their impressions. Their impression times can only be cut to slightly more than five-minutes with experience. The impression time, which averaged 515.52 seconds or just less than 8.6 minutes, includes 
the time the participant took to evaluate the impression prior to handing it to the investigator.

Scan Time took significantly longer than impression time: more than twice as long. Many variables contributed to this value, most of which are overcome with experience. For example, increased stability handling of the wand, more efficient angulation for hard to reach areas such as interproximals, quicker transitions from occlusal to lingual to buccal surfaces, and more effective powdering. It was noted during the exercise that participants spent a disproportionate amount of time scanning the abutment and the interproximals when compared to the rest of the dentition. More effective wand placement would dramatically reduce time spent focusing these tough areas into the scanning wand's depth of field.

Some participant-made impressions were not clinically acceptable according to the clinical acceptability forms. In the case of conventional impressions, participants were informed of the areas that were deficient and were asked to re-impress their typodont. Only 3 conventional impressions required remake. These times were added to the previous totals to simulate the amount of chair time an impression would necessitate if an impression needed to be remade. In the case of digital impressions, areas of deficiency were identified and the participant asked to re-scan the area or, if necessary, re-powder and re-scan. These times were added accordingly. Number of re-scans for digital were not recorded because entire scan were not needed to be remade due to the ability to spot-add missing data. 
Following their participation in impression making, participants filled out a postexposure questionnaire. Questions were written to reflect Domain C of the pre-exposure questionnaire so that comparisons could be made and changes detected.

Participants' mean age was 25, with a standard deviation (SD) of 2.31. This means most participants were born within a couple years of 1989, and they grew up in the 90's. This is potentially significant, as this generation of individuals grew up with advanced gaming systems and digital technology that potentially challenged them to remotely control monitor-based activities from a young age. Theirs is also an age group that saw many gadgets develop from analog predecessors into newer digital versions. A possible bias related to this age group is their exposure to digital systems, such as computers, watches, radios, etc may have been sufficient to instill a belief in the inherent superiority of digital appliances versus analog versions, thereby instilling in them a bias towards the digital method.

In the pre-exposure questionnaire participants reported a stronger familiarity with PVS impression systems as compared to the digital. This is likely the result of classroom lectures on the various impression materials as well as the known similarity between alginate and PVS techniques. Although it should be noted, no lectures had been given regarding the manner of PVS impression technique; only it's physical characteristics. It is also more likely students would have seen PVS impressions taken while shadowing in the clinic, both as a pre-dental student and as a freshman dental student.

One could have expected that participants would believe it easier to make an impression using a method with which they are so much more familiar. As we see in Table 4 this was not the case. There was no difference in pre-exposure expectation for 
Participant's Ease of Use Level between the two techniques. It seems that despite participants' familiarity with conventional impressions, they expected digital impressions to be just as easy.

Similarly, no difference in participant's Ease of Use Level was detectable after exposure. It seems participants found the two techniques equally as easy to work with, which bodes well for dental education. If students don't perceive the digital technique as more difficult, it may suggest their willingness to improve their technique, thereby reducing the time spent making impressions. The only measureable change in expected and experienced Ease of Use Level was with PVS before and after exposure. Participants felt the PVS technique was even easier than initially anticipated. Participants found no statistical difference in their expected and experienced ease of use with the digital system.

Participants were also asked how many digital impressions would be expected before attaining a level of competency fit for clinical practice. Before trying a digital impression the expectation was averaged 5.5 attempts to competency. Following their experience the average dropped to 3.9. In contrast, the ease of use for the digital system was very nearly the same before and after exposure, dropping slightly from 3.84 to 3.56 . These results suggest a participant statement such as "The digital impression was more or less as easy as I thought it would be, but I can see myself getting better at it more quickly than I previously expected." This bodes well for future integration of this technology into an already busy academic curriculum. One participant commented, "I believe this technology is excellent and although it does have a learning curve, it will ultimately be faster and easier than conventional methods. I would like to employ this in a future practice." 
$92 \%$ of participants responded 'yes' to the expectation that the digital impression system would become their primary impression technique as some point during their careers. This increased to $96 \%$ after exposure. After trying the digital system, all but one participant expected this technology to become their primary method for taking dental impressions. Fewer expected to incorporate this technology right away. $76 \%$ responded positively, pre-exposure, regarding their expectation to use this technology in their first job as a dental professional. This reduced to $64 \%$ after trying it out. In the open response portion of the post-exposure questionnaire a participant pointed out the room for improvement, "I believe bugs will get worked out and the technology will become faster, smarter, better. I'm excited about the potential growth. It was fun!"

Participants were asked about their expectations for digital impression technology to save time and money in the dental office. $72 \%$ expected the digital system to save more time in their future practice before trying it. This reduced to $64 \%$ expecting a savings of time. This is related to the finding that the conventional impression method turned out to be easier than previously expected. The expectation for financial savings went up from $56 \%$ believing the digital impression would provide greater savings pre-exposure to $68 \%$ post-exposure. Fewer than three participants (out of twenty-five) expected conventional impression methods to provide an advantage of either time or money. The remaining responses were undecided. A participant expressed his concern about the current cost of digital impression technology, stating "it will save money over using conventional impression materials. Hopefully, enough to offset the equipment's cost." The expectation of a high price tag associated with large equipment in a budding technological field left 
many participant's undecided. After trying both impression techniques, only one participant believed the conventional method would be more cost-efficient.

Finally, participants were asked directly whether they feel their experience with the digital scanner changed their opinion regarding the usefulness of this technology. $72 \%$ of participants said the experience did change their opinion for the better. Multiple participants wrote comments that echoed the following: "No, I've thought digitizing impressions should be the norm in the near future." This suggests pre-existing expectations played a large role in patient responses, in this case limiting participants' opinions from improving. It is noteworthy to mention that zero participants' opinions worsened after exposure.

Existing literature demonstrates operator and patient preferences, quality of impression accuracy, and learning curves that suggest an increase in rapidity with multiple practice attempts. This research demonstrates students' high expectations for this technology, which should be cultivated for research and practical gains. The results also demonstrate the relative increase in time that will be necessary in the classroom and preclinical laboratory. Future research should continue to identify differences between systems and help guide educational techniques to make digital impression education more efficient and effective. The digital impression is the way of the future and current dental students are ready to embrace it...if only someone would show them how to use it. 


\section{CHAPTER 7 \\ CONCLUSIONS}

Within the limitations of this study, the following conclusions can be drawn:

\section{Time}

- More didactic instruction time is likely to be needed to introduce DMD students to chairside digital scanning systems than currently allotted for PVS education.

- More pre-clinical instruction time is likely to be needed for DMD students to attain competency with digital scans compared with PVS impressions.

\section{Existing Familiarity}

- Students are likely to exhibit less pre-existing familiarity with digital impressions than with PVS methods.

\section{Perceived Ease of Use Level}

- Prior to experiencing both techniques, DMD students are likely to exhibit no difference in expected ease of use level.

- After experiencing both techniques, DMD students are likely to exhibit no difference in experienced ease of use levels. 
- PVS impression techniques are likely to prove for DMD students than they initially might anticipate.

\section{Future Expectations}

- DMD students are likely to have strong positive opinions towards digital scans before and after exposure.

- DMD students are likely to attain clinical competency quicker than they may initially anticipate.

- DMD students are likely to expect digital impressions systems to play a prominent role during their professional lifetimes.

- DMD students are likely to expect digital impression systems to provide the opportunity for increased financial and clinical efficiency.

- DMD students are likely to expect digital impression systems to become their primary impression technique at some point during their career. 


\section{REFERENCES}

Poticny DJ, Klim J. (2010) CAD/CAM In-Office Technology: Innovations after 25 years for predictable, esthetic outcomes. Journal of the American Dental Association, 141(6 suppl):5S-9S.

Luthardt RG, Loos R, \& Quaas, S. (2005) Accuracy of intraoral data acquisition in comparison to the conventional impression. International Journal of Computerized Dentistry, 8(4), 283-294. Retrieved from Medical Literature Analysis and Retrieval System Online, MEDLINE.

Fasbinder, D. (2012) Using digital technology to enhance restorative dentistry. Compendium of Continuing Education in Dentistry, 33(9), 666-672. Retrieved from Medical Literature Analysis and Retrieval System Online, MEDLINE.

Wismeijer, D, Mans, R, van Genuchten, M, \& Reijers, HA. (2013) Patients' preferences when comparing analogue implant impressions using a polyether impression material versus digital impressions (Intraoral Scan) of dental implants. Clinical Oral Implants Research, 25(10):1113-8 doi:10.1111/clr.12234.

Ting-Shu, S, Jian, S. (2014) Intraoral Digital Impression Technique: a Review. Journal of Prosthodontics. Epub ahead of print, Sept 14, 2014. Doi: 10.1111/jopr.12218

Farah JW, Brown L. (2009) Integrating the 3M ESPE LAVA Chairside Oral Scanner C.O.S into Daily Clinical Practice. The Dental Advisor. June 2009 (12):1-4

Oosterink FMD, De Jongh A, Hoogstraten J. (2009) Prevalence of dental fear and phobia relative to other fear and phobia subtypes. European Journal of Oral Sciences. 117(2):135-143. doi: 10.1111/j.1600-0722.2008.00602.x

Locker D, Shapiro D, Liddell A. (1996) Negative Dental Experiences and their Relationship to Dental Anxiety. Community Dental Health, 13(2):86-92. Retrieved from MEDLINE.

Akarslan ZZ, Yildirim Biçer AZ. (2013) Influence of gag reflex on dental attendance, dental anxiety, self-reported temporomandibular disorders and prosthetic restorations. Journal of Oral Rehabilitation, 40(12):932-9. doi: $10.1111 /$ joor. 12106 
Maggirias J, Locker D. (2002) Five-Year Incidence of Dental Anxiety in an Adult Population. Community Dental Health, 19(3):173-179. Retrieved from MEDLINE.

Yuzbasioglu, E, Kurt, H, Turunc, R, \& Bilir H. (2014) Comparison of digital and conventional impression techniques: evaluation of patients' perception, treatment comfort, effectiveness and clinical outcomes. BMC Oral Health, 14(10), 1-7. doi: 10.1186/1472-6831-14-10.

Gimenez B, Ozcan M, Pradies G. (2013) Accuracy of a Digital Impression System Based on Active Wavefront Sampling Technology for Implants Considering Operator Experience, Implant Angulation, and Depth. Clinical Implant Dentistry and Related Research. July 24. doi: 10.1111/cid.12124

Galhano GA, Pellizzer EP, Mazaro JV. (2012) Optical Impression Systems for CAD/CAM restorations. Journal of Craniofacial Surgery. 23(6):e575-9. doi:10.1097/SCS.0b013e31826b8043

Seelbach P, Brueckel C, Wöstmann B. (2012) Accuracy of Digital and Conventional Impression Techniques and Workflow. Clinical Oral Investigation. 17:17591764. doi:10.1007/s00784-012-0864-4

Neves FD, Prado CJ, Soares CJ. (2014) Micro-Computed Tomography Evaluation of Marginal Fit of Lithium Disilicate Crowns Fabricated by Using Chairside CAD/CAM Systems or the Heat-Pressing Technique. Journal of Prosthetic Dentistry. 112(5):1134-40. doi. 10.1016/j.prosdent.2014.04.028.

Anadioti E, Aquilino SA, Qian F. (2014) 3D and 2D Marginal Fit of Pressed and CAD/CAM Lithium Disilicate Crowns made from Digital and Conventional Impressions. Journal of Prosthodontics. July 3. doi: 10.1111/jopr.12180.

Tidehag P, Ottosson K, Sjogren G. (2014) Accuracy of ceramic restorations made using an in-office optical scanning technique: an in vitro study. Operative Dentistry. 39(3):308-16 doi:10.2341/12-309-L

Abdel-Azim T, Zandinejad A, Lin W, Morton D. (2014) The Influence of Digital Fabrication Options on the Accuracy of Dental Implant-Based Single Units and Complete-Arch Frameworks. The International Journal of Oral and Maxillofacial Implants. 29(6):1281-88. doi: 10.11607/jomi.3577

Al Quran FA, Rashdan BA, Zomar AA, Weiner S. (2012) Passive Fit and Accuracy of Three Dental Implant Impression Techniques. Quintessence Int. 43:119-125

Silva, Erdelt K, Edelhoff D, Guth JF. (2014) Marginal and Internal Fit of Four-Unit Zirconia Fixed Dental Prostheses Based on Digital and Conventional Impression Techniques. Clinical Oral Investigations. 18(2):515-23 doi: 10.1007/s00784013-0987-2. 
Boening KW, Wolf BH, Walter MH. (2000) Clinical Fit of Procera AllCeram Crowns. Journal of Prosthetic Dentistry. 84(4):419-24. doi: 10.1067/mpr.2000.109125

Molin M, Karlsson S. (1993) The Fit of Gold Inlays and Three Ceramic Inlay Systems. A Clinical and In Vitro Study. Acta Odontologica Scandanavica. 51(4):201-6. Retrieved from Medline.

Nassar U, Oko A, Flores-Mir C. (2013) An in vitro study on the Dimensional Stability of a Vinyl Polyether Silicone Impression Material Over a Prolonged Storage Period. The Journal of Prosthetic Dentistry. 109(3):172-8. doi: 10.1016/S00223913(13)60038-4

Ender A, Mehl A. (2011) Full Arch Scans: Conventional vs Digital Impressions-an In Vitro Study. International Journal of Computerized Dentistry. 14(1):11-21. Retrieved from MEDLINE.

Ender A, Mehl A. (2014) Accuracy of Complete Arch Dental Impressions: a New Method of Measuring Trueness and Precision. Journal of Prosthetic Dentistry. 109(2):121-8 doi:10.1016/S0022-3913(13)60028-1

Kim SY, Kim MJ, Kwon HB. (2013) Accuracy of Dies Captured by an Intraoral Digital Impression System Using Parallel Confocal Imaging. International Journal of Prosthodontics. 26(2):161-3 doi: 10.11607/ijp.3014

Hendricson WD. (2012) Changes in Education Methodologies in Predoctoral Dental Education: Finding the Perfect Intersection. Journal of Dental Education. 76(1):118-141

Janda SM, Botticelli TA, Attström R. (2005) Computer-mediated instructional video: a randomised controlled trial comparing a sequential and a segmented instructional video in surgical hand wash. European Journal of Dental Education. 9(2):53-58 doi:10.1111/j.1600-0579.2004.00366.x

Eitner S, Holst S, Schlegel A. (2008) Comparative Study on Interactive Learning Computer-Aided-Learning and Computer-Aided-Testing in Patient-Based Dental Training in Maxillofacial Surgery. European Journal of Dental Education. 12(1):35-40. doi. 10.1111/j.1600-0579.2007.00490.x

Aragon CE, Zibrowski EM. (2008) Does Exposure to a Procedural Video Enhance Preclinical Dental Student Performance in Fixed Prosthodontics? Journal of Dental Education. 72(1):67-71. doi

Hu J, Yu H, Shao J, Wang Y. (2009) Effects of Dental 3D Multimedia System on the Performance of Junior Dental Students in Preclinical Practice: a Report From China. Advances in Health Sciences Education: theory and practice. 14(1):12333. doi: 10.1007/s10459-007-9096-9 
Nunez, DW, Taleghani, M, Wathen, WF, \& Abdellatif HM. (2012) Typodont versus live patient: predicting dental students' clinical performance. Journal of Dental Education, 76(4), 407-413. Retrieved from Medical Literature Analysis and Retrieval System Online, MEDLINE.

Lee, SJ, \& Gallucci, GO. (2013) Digital vs. conventional implant impressions: efficiency outcomes. Clinical Oral Implants Research, 24(1), 111-115. doi:10.1111/j.16000501.2012.02430.x.

Lee, SJ, MacArthur IV, RX, \& Gallucci, GO. (2013) An evaluation of student and clinician perception of digital and conventional implant impressions. Journal of Prosthetic Dentistry, 110(5), 420-423. doi:10.1016/j.prosdent.2013.06.012.

Joda T, Bragger U. (2014) Complete Digital Workflow for the Production of ImplantSupported Single-Unit Monolithic Crowns. Clinical Oral Implants Research. 25(11):1304-6. doi:10.1111/clr.12270

Lin WS, Metz MJ, Morton D. (2014) Digital Data Acquisition for a CAD/CAMFabricated Titanium Framework and Zirconium Oxide Restorations for an Implant-Supported Fixed Complete Dental Prosthesis. Journal of Prosthetic Dentistry. 112(6):1324-9. doi: 10.1016/j.prosdent.2014.06.012

Patel, N. (2010) Incorporating three-dimensional digital technologies for comprehensive implant dentistry. Journal of the American Dental Association. 141 suppl 2:20S4S. doi:10.14219/jada.archive.2010.0357.

Commission on Dental Accreditation. Standard 2-Education Programs, Standard 223Accreditation Standards For Dental Education Programs. American Dental Association, 2013. pp. 29 
Appendix A - MATERIALS

General Purpose

- Stopwatch

- Laptop

- PVS impression technique video (Altered by Alexander M Marti MD, ULSD, Louisville, KY with permission from Stephen Mattingly DMD, ULSD, Louisville, $\mathrm{KY})$

- 3M LAVA educational presentation (WeiShao Lin DMD, ULSD, Louisville, KY)

PVS Impressions

- Light Body - Aquasil Ultra XLV (Densply, York, Pennsylvania, USA)

- Heavy Body - Aquasil Ultra Heavy (Densply, York, Pennsylvania, USA)

- Tray Adhesive - Caulk Tray Adhesive (Dentsply, York, Penssylvania, USA)

- V.P.S. Tray Adhesive (Kerr Corp., Romulus, MI, USA)

- Triple Trays -

- PVS dispensing gun system -

- Large Auger Tip - High Performance Mixing Tips (Patterson Dental, St. Paul, MN, USA)

- Small Auger Tip - High Performance Mixing Tips (Patterson Dental, St. Paul, MN, USA)

- Fine point tips for small auger tips - High Performance Intraoral Tip (Patterson Dental, St. Paul, MN, USA) 
Digital Impressions

- LAVA C.O.S. - (3M ESPE, Seefeld, Germany)

- Titanium Dioxide Powder - (3M ESPE, Seefeld, Germany) 
MATERIAL LOT \#s

\begin{tabular}{|l|l|l|l|}
\hline Participant \# & Heavy Body & Light Body & Tray Adhesive \\
\hline 1 & $130529 \exp 05 / 16$ & $130226 \exp 02 / 16$ & $130502 \exp 05 / 17$ \\
\hline 3 & $130128 \exp 01 / 16$ & $130226 \exp 02 / 16$ & $130502 \exp 05 / 17$ \\
\hline 4 & $1304041 \exp 04 / 16$ & $130226 \exp 02 / 16$ & $130502 \exp 05 / 17$ \\
\hline 9 & $1304041 \exp 04 / 16$ & $130226 \exp 02 / 16$ & $130502 \exp 05 / 17$ \\
\hline 10 & $1304041 \exp 04 / 16$ & $130226 \exp 02 / 16$ & $130502 \exp 05 / 17$ \\
\hline 11 & $130529 \exp 05 / 16$ & $130226 \exp 02 / 16$ & $130502 \exp 05 / 17$ \\
\hline 12 & $1304041 \exp 04 / 16$ & $130226 \exp 02 / 16$ & $3-1169 \exp 06 / 16$ \\
\hline 13 & $130128 \exp 01 / 16$ & $130226 \exp 02 / 16$ & $130502 \exp 05 / 17$ \\
\hline 14 & $130128 \exp 01 / 16$ & $130226 \exp 02 / 16$ & $130502 \exp 05 / 17$ \\
\hline 15 & $130128 \exp 01 / 16$ & $130226 \exp 02 / 16$ & $130502 \exp 05 / 17$ \\
\hline 16 & $130128 \exp 01 / 16$ & $130226 \exp 02 / 16$ & $130502 \exp 05 / 17$ \\
\hline 17 & $1304041 \exp 04 / 16$ & $130226 \exp 02 / 16$ & $130502 \exp 05 / 17$ \\
\hline 18 & $1304041 \exp 04 / 16$ & $130226 \exp 02 / 16$ & $130502 \exp 05 / 17$ \\
\hline 19 & $1304041 \exp 04 / 16$ & $130226 \exp 02 / 16$ & $130502 \exp 05 / 17$ \\
\hline 20 & $1304041 \exp 04 / 16$ & $130226 \exp 02 / 16$ & $130502 \exp 05 / 17$ \\
\hline 21 & $1304041 \exp 04 / 16$ & $130226 \exp 02 / 16$ & $3-1169 \exp 06 / 16$ \\
\hline 22 & $1304041 \exp 04 / 16$ & $130226 \exp 02 / 16$ & $130502 \exp 05 / 17$ \\
\hline 23 & $1304041 \exp 04 / 16$ & $130226 \exp 02 / 16$ & $130502 \exp 05 / 17$ \\
\hline 24 & $1304041 \exp 04 / 16$ & $130226 \exp 02 / 16$ & $3-1169 \exp 06 / 16$ \\
\hline 25 & $1304041 \exp 04 / 16$ & $130226 \exp 02 / 16$ & $3-1169 \exp 06 / 16$ \\
\hline 26 & $1304041 \exp 04 / 16$ & $130226 \exp 02 / 16$ & $3-1169 \exp 06 / 16$ \\
\hline 27 & $1304041 \exp 04 / 16$ & $130226 \exp 02 / 16$ & $3-1169 \exp 06 / 16$ \\
\hline 28 & $1304041 \exp 04 / 16$ & $130226 \exp 02 / 16$ & $3-1169 \exp 06 / 16$ \\
\hline 29 & $13041 \exp 04 / 16$ & $130226 \exp 02 / 16$ & $3-1169 \exp 06 / 16$ \\
\hline
\end{tabular}


Appendix B - Pre-Exposure Questionnaire

Participant ID\#

Date

\section{Pre-Exposure Questionnaire}

INSTRUCTIONS: Before beginning the impression technique exercises respond to the following questions and return this form to the investigator present. For questions with a Likert scale from 1-5, please circle the response that represents how closely you feel towards either end of the answer spectrum. On multiple choice questions please select the single closest response. Please be truthful.

\section{A. Demographic Information:}

1. What is your age?

2. Did you have any professional experience in dentistry prior to entering the University of Louisville School of Dentistry?

Please Explain:

3. Immediately after graduating from ULSD, in which of the following areas of dental practice do you plan to become immediately involved?

$\square$ General Dental Practice

Specialty, if so which specialty

AEGD/GPR Program

Not practicing

B. Existing familiarity of impression techniques:

1. How familiar are you with digital intraoral impression technology?

Very Unfamiliar

Unfamiliar

Neutral

Somewhat

familiar

Very Familiar

1

2 3

4 5 
2. How familiar are you with taking conventional impressions with polyvinylsiloxane (PVS)?

Very Unfamiliar Unfamiliar Neutral Somewhat familiar Very Familiar

$1 \_3$

3. How familiar do you consider yourself at operating computer software and/or other digital/electronic devices?

Very Unfamiliar Unfamiliar Neutral Somewhat familiar Very Familiar

$1 \_3 \quad 3 \quad 4 \quad 5$

C. Pre-Exposure Perceptions and Future Expectation:

1. How easy/difficult do you expect it to be to take conventional impressions? Very Difficult Difficult Neutral Easy Very Easy $\quad 1 \ldots 2+3 \ldots$

2. How easy/difficult do you expect it to be to take digital impressions? $\begin{array}{llll}\text { Very Difficult Deutral Dasy } & \text { Difficult }\end{array}$ Easy $\quad 1 \ldots 2+3+4+5$

3. How many impressions do you think you will need to take before you feel comfortable and competent enough to use a digital scanner on a live patient in the clinic?

Answer:

4. With experience, which technique do you expect would save you the most time in your dental office?

$\square$ Conventional impression

$\square$ Digital impression system

$\square$ I don't know 
5. With experience, which technique do you expect would save you the most money in your dental office?

$$
\begin{aligned}
& \square \text { Conventional impression } \\
& \text { Digital impression system } \\
& \square \text { I don't know }
\end{aligned}
$$

6. Do you expect to have a digital scanner for impressions within your first job as a dental professional?

$$
\begin{aligned}
& \square \text { Yes } \\
& \square \text { No }
\end{aligned}
$$

7. Do you expect to use a digital scanner as your primary impression technique at some point in your career?

$$
\begin{aligned}
& \square \text { Yes } \\
& \square \text { No }
\end{aligned}
$$

8. Digital scanning techniques will completely replace conventional impression techniques for routine impressions during my lifetime

Strongly Disagree Disagree Neutral Agree Strongly Agree

$$
1
$$

2 3

$4 \quad 5$




\section{Appendix C - Pre-Exposure Questionnaire}

Participant ID\#

Date

\section{Post-Exposure Questionnaire}

INSTRUCTIONS: Now that you have completed the impression exercises respond to the following questions and return this form to the investigator present. For questions with a Likert scale from 1-5, please circle the response that represents how closely you feel towards either end of the answer spectrum. On multiple choice questions please select the single closest response. Please be truthful.

1) Which technique was easier to perform?

$\square$ PVS impression

LAVA C.O.S (3M ESPE)

2) How easy/difficult was it to use PVS to take impressions?

$\begin{array}{ccccc}\text { Very Difficult } & \text { Difficult } & \text { Neutral } & \text { Easy } & \text { Very Easy } \\ 1 & 2 & 3 & 4 & 5\end{array}$

3) How easy/difficult was it to use the LAVA C.O.S (3M ESPE) intraoral scanner?

$\begin{array}{ccccc}\text { Very Difficult } & \text { Difficult } & \text { Neutral } & \text { Easy } & \text { Very Easy } \\ 1 & 2 & 3 & 4 & 5\end{array}$

4) How many impressions do you think you will need to take before you feel comfortable and competent enough to use a digital scanner on a live patient in the clinic?

Answer:

5) With experience, which technique do you expect would save you the most time in your dental office?

Conventional Impression

$\square$ Digital Impression System

$\square$ I don't know 
6) With experience, which technique do you expect would save you the most money in your dental office?

$$
\begin{aligned}
& \square \text { Conventional Impression } \\
& \square \text { Digital Impression System } \\
& \square \text { I don't know }
\end{aligned}
$$

7) Do you expect to have a digital scanner available to you in your first job as a dental professional?

$$
\begin{aligned}
& \square \text { Yes } \\
& \square \text { No }
\end{aligned}
$$

8) Do you expect to use a digital scanner as your primary impression technique at some point in your career?

$$
\begin{aligned}
& \square \text { Yes } \\
& \square \text { No }
\end{aligned}
$$

9) Digital scanning techniques will completely replace conventional impression techniques for routine impressions during my lifetime

$\begin{array}{ccccc}\text { Strongly Disagree } & \text { Disagree } & \text { Neutral } & \text { Agree } & \text { Strongly Agree } \\ 1 & 2 & 3 & 4 & 5\end{array}$

10) How has learning to use an intraoral scanner changed your opinion of the usefulness of the technology?

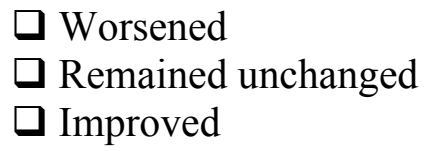

Has your experience with chair-side scanners changed your views on the budding technology's usefulness in the near or distant future? If so, please explain. 
Appendix D - Clinical Acceptability Forms

Participant ID\#

Date

\section{Master Impression with PVS material}

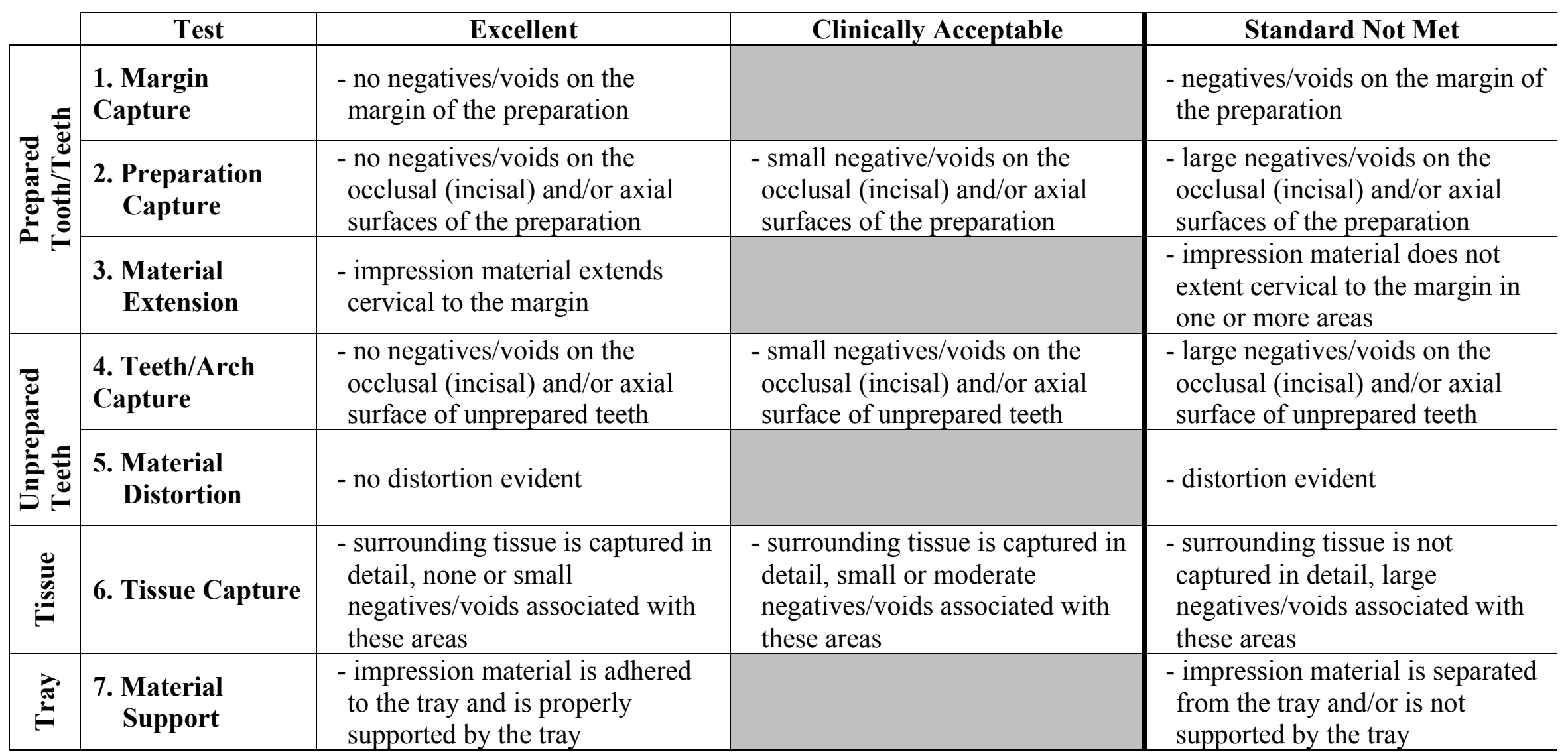


Master Impression with Intraoral Scanner

Date

\section{LAVA C.O.S (3M ESPE)}

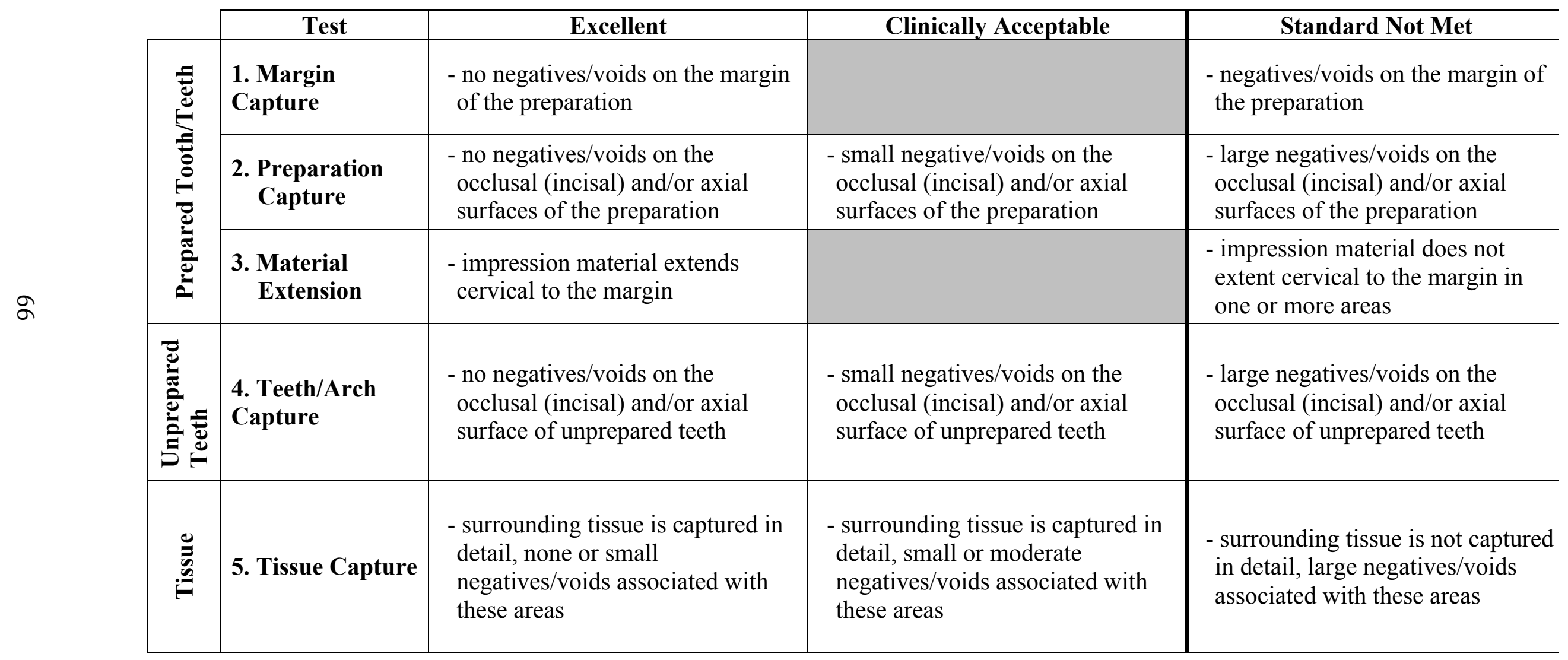




\section{CURRICULUM VITA}

NAME: $\quad$ Alexander M. Marti

ADDRESS: 1030 Mulberry Street

Louisville, KY 40217

DOB: $\quad$ Louisville, KY - September 4, 1985

\section{EDUCATION}

\& TRAINING: $\quad$ B.A. Spanish

University of Louisville

2004-2008

B.A. Biology

University of Louisville

2004-2008

Doctor of Medicine

University of Louisville

School of Medicine

2008-2012

Doctor of Dental Medicine

University of Louisville

School of Dentistry

2012- expected graduation, May 2016

AWARDS: $\quad$ Dental Scholarship Award

Oral Health Foundation

Pierre Fauchard Academy

2014

Greenberg Award for Research in Medical Education

Research Louisville!

2013

General Dentistry Scholarship

University of Louisville

School of Dentistry, 2012-2016 
Foundation Award

Hispanic Dental Association

2012

PROFESSIONAL SOCIETIES

Hispanic Student Dental Association

Member

2012-present

American Student Dental Association

Member

2012-present

Kentucky Dental Association

UofL Student Representative

2012-present

NATIONAL MEETING PRESENTATIONS

Research Louisville!

Poster Session

2013

National Hispanic Medical Association

Poster Session

2011 